ESCUELA DE HUMANIDADES

CARRERA DE PSICOLOGÍA

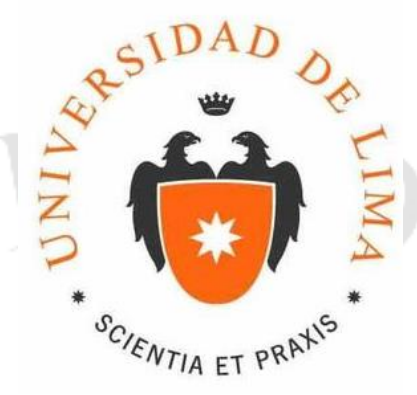

\title{
DISFUNCIÓN FAMILIAR EN \\ ADOLESCENTES DE QUINTO DE \\ SECUNDARIA DE UN COLEGIO PÚBLICO Y \\ UN COLEGIO PRIVADO EN EL DISTRITO \\ DE LA MOLINA
}

Tesis para optar el título de Licenciado en Psicología

Presentada por

María Jesús Escobar Sáez

Código 20071435

Asesor

Mariela Dejo Vasquez

Lima- Perú

Setiembre 2015 


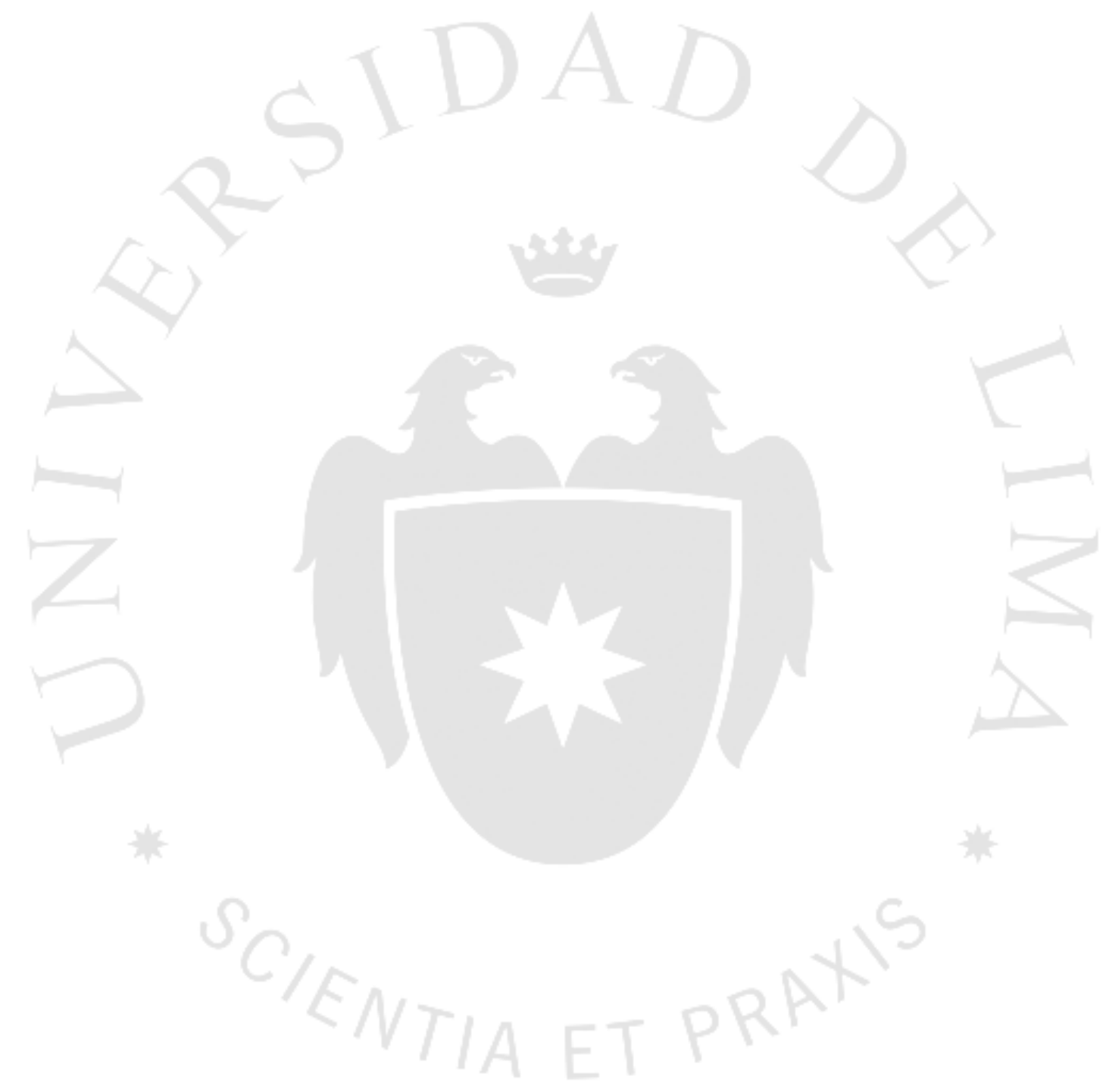




\section{DISFUNCIÓN FAMILIAR EN}

\section{ADOLESCENTES DE QUINTO DE}

SECUNDARIA DE UN COLEGIO PÚBLICO Y

UN COLEGIO PRIVADO EN EL DISTRITO

DE LA MOLINA 


\section{ÍNDICE}

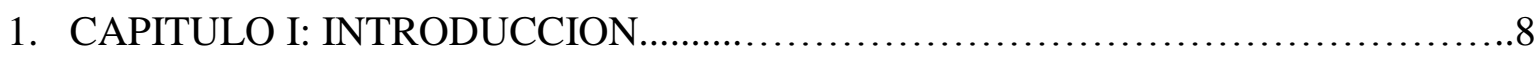

1.1 Descripción del problema................................................... 8

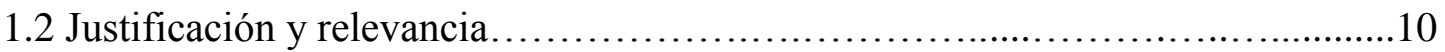

1.3 Limitaciones............................................................ 11

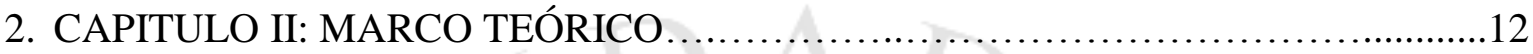

2.1 Investigaciones antecedentes......................................... 12

2.1.1 Antecedentes nacionales..........................................12

2.1.2 Antecedentes internacionales......................................14

2.2 Marco conceptual................................................... 18

2.2.1 La familia......................................................... 18

2.2.1.1 La familia como sistema................................18

2.2.1.2 Rol de los padres......................................19

2.2.1.2.1 Rol de la madre...................................20

2.2.1.2.2 Rol del padre...................................21

2.2.1.4 Ciclo vital familiar..........................................22

2.2.2 La adolescencia..............................................23

2.2.2.1 La adolescencia temprana...............................23

2.2.2.2 La adolescencia intermedia.............................24

2.2.2.3 La adolescencia tardía...................................24

2.2.2.4 El desarrollo cognitivo en la adolescencia....................25

2.2.2.5 Diferencias en el sexo...................................26

2.2.3 La familia en la adolescencia...................................26

2.2.4 Funcionamiento Familiar..........................................28

2.2.4.1 Cohesión familiar..........................................30

2.2.4.2 Adaptabilidad familiar......................................30

2.2.4.3 Comunicación familiar.....................................30

2.2.5 Familia disfuncional.............................................. 35

2.2.6 Familia Peruana...................................................... 32

2.2.7 Nivel socioeconómico.......................................... 32

3. CAPITULO III: OBJETIVOS, HIPÓTESIS Y DEFINICIÓN DE VARIABLES..........34 


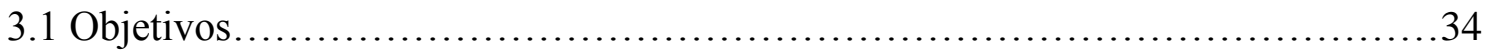

3.2 Hipótesis......................................................... 35

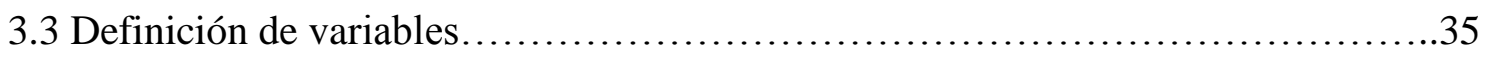

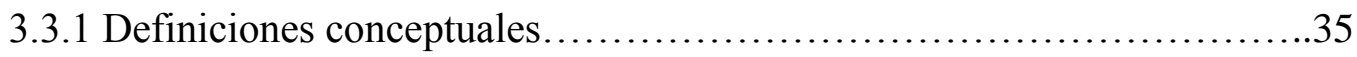

3.3.1.1 Disfunción familiar........................................35

3.3.1.2 Nivel socioeconómico....................................36

3.3.2 Definiciones operacionales....................................... 36

3.3.2.1 Disfunción familiar.......................................36

3.3.2.2 Nivel socioeconómico.....................................36

4. CAPITULO IV: METODO................................................... 37

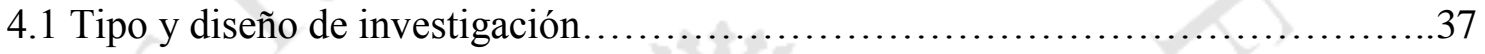

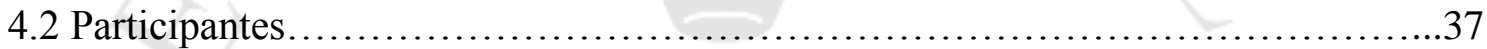

4.3 Técnicas de recolección de datos.......................................... 38

4.3.1 Inventario de disfunción familiar (IDF) ........................... 38

4.3.1.1 Confiabilidad y validez..................................39

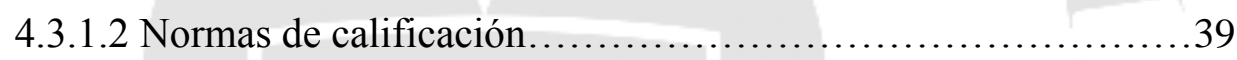

4.4 Procedimiento de recolección de datos...............................................................

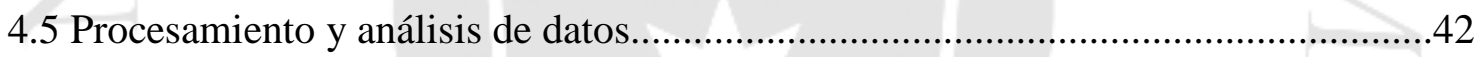

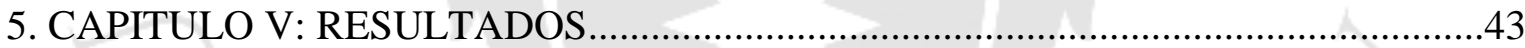

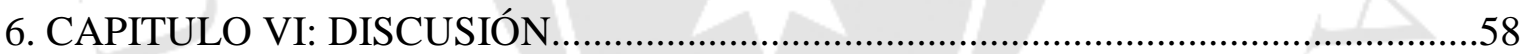

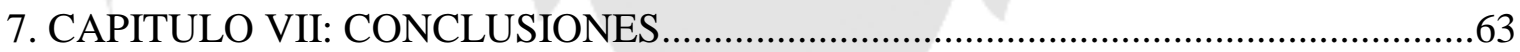

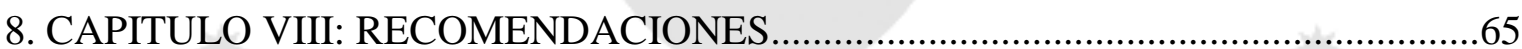

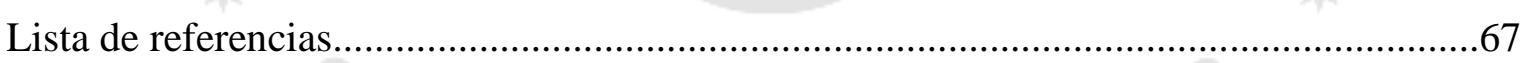

Anexos

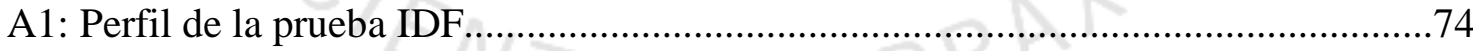

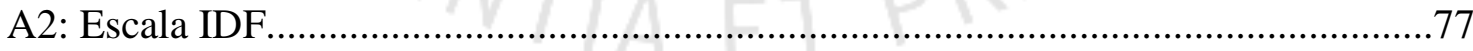

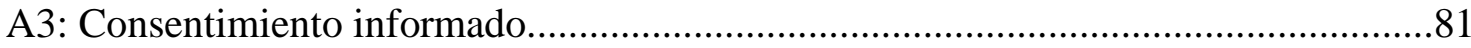




\section{ÍNDICE DE TABLAS}

Tabla 5.1: Estimación de la confiabilidad del factor1: Comunicación

Tabla 5.2: Estimación de la confiabilidad del factor 2: Adaptación.

Tabla 5.3: Estimación de la confiabilidad del factor 3: Bienestar.

Tabla 5.4: Estimación de la confiabilidad del factor 4: Autonomía

Tabla 5.5: Estimación de la confiabilidad del factor 5: Rol

Tabla 5.6: Evidencia de la validez de constructo de la Escala IDF a través del análisis factorial exploratorio.

Tabla 5.7: Prueba K-S de bondad de ajuste a la curva normal del IDF de acuerdo al tipo de colegio

Tabla 5.8: Datos descriptivos del puntaje total y factores de la prueba IDF según el tipo de colegio.......

Tabla 5.9: Resultados de la prueba $U$ de Mann-Whitney según tipo de colegio de los participantes.

Tabla 5.10: Prueba K-S de bondad de ajuste a la curva normal del IDF de acuerdo al sexo......

Tabla 5.11: Datos descriptivos del puntaje total y factores de la prueba IDF según el sexo de los participantes......

Tabla 5.12: Resultados de la prueba $U$ de Mann-Whitney según tipo el sexo de los participantes. .54

Tabla 5.13: Prueba K-S de bondad de ajuste a la curva normal del IDF de acuerdo a la presencia de los progenitores en el hogar

Tabla 5.14: Datos descriptivos del puntaje total y factores de la prueba IDF según la presencia de los progenitores en el hogar

Tabla 5.15: Resultados de la prueba $U$ de Mann-Whitney según la presencia de los progenitores en el hogar. 


\section{DISFUNCIÓN FAMILIAR EN ADOLESCENTES DE QUINTO DE SECUNDARIA DE UN COLEGIO PÚBLICO Y UN COLEGIO PRIVADO EN EL DISTRITO DE LA MOLINA}

Resumen

La investigación tuvo como objetivo analizar las diferencias en el nivel de disfunción familiar en adolescentes de quinto de secundaria de un colegio privado y un colegio público en el distrito de La Molina. Además, determinar si existen diferencias según el sexo y según la presencia de padres en el hogar en los niveles de disfunción. La muestra estuvo compuesta de 214 alumnos entre 15 y 19 años de edad, donde 106 de ellos eran del colegio público y 107 del privado. Se utilizó el Inventario de Disfunción Familiar (IDF) para determinar el nivel de disfunción familiar. Se obtuvo como resultado que existen diferencias significativas en el nivel de disfunción según el colegio de procedencia y según el sexo, sin embargo, no se encontraron diferencias según la presencia de uno o ambos de los progenitores en el hogar.

Palabras claves: Disfunción familiar, adolescencia, nivel socioeconómico.

\section{Abstract}

The research was aimed to analyze the differences in the level of family dysfunction in adolescents in senior year in both a private and a public school in the district of La Molina. Also, to determine if there are differences according to gender, the presence of parents in the home in the levels of dysfunction. The sample consisted of 214 students between 15 and 19 years old, 106 of them were from a public school and 107 from a private one. Family Dysfunction Inventory (IDF) was used to determine the level of family dysfunction. The results showed that there are significant differences in the level of dysfunction according to the school of origin and by gender, however, no difference was found for the presence of one or both of the parents at home.

Key words: family dysfunction, aadolescence, socioeconomic level. 


\section{CAPITULO I: INTRODUCCIÓN}

\subsection{Descripción del problema}

En las últimas décadas, la familia, como base de la sociedad, ha pasado por diversos cambios. Según Llavona (2012) en los últimos cincuenta años ha sufrido una rápida, brusca y profunda transformación que ha afectado a las características de los que integran la familia y las funciones que desempeñaban. Estos cambios han sido: una disminución en la producción de hijos y un cambio en la erosión de poder de los padres. Asimismo, estos cambios están ligados a la pérdida de contacto interpersonal y calidez en los lazos, deterioro de la comunicación interpersonal y poca claridad en los roles que debe cumplir cada miembro dentro de una familia. Talledo (2011) señala que de acuerdo a un estudio realizado por el Instituto de ciencias para la familia de la Universidad de Piura, el Perú ocupa el penúltimo lugar en la tasa bruta de matrimonios y el segundo puesto en el porcentaje de adultos que prefieren convivir entre 29 países del mundo. Lo cual nos lleva comprender que en el Perú, la familia no llega a ser uno de los aspectos más importantes, llegando a existir una distorsión de aquello que conocemos como familia.

Morelos (2010) señala que el 50\% de niños que asisten a terapias psicológicas provienen de familias disfuncionales, estos son niños que en su mayoría poseen problemas de aprendizaje y desintegración familiar. Esta última puede ser provocada por violencia intrafamiliar, depresión o problemas de aprendizaje en algún miembro.

Revuelta y Alberti (2008) señalan que la familia es un factor trascendental e importante en el desarrollo del individuo ya que esta es la fuente principal de nuestras creencias y pautas de comportamiento relacionadas con la salud. Asimismo, Viguer y Serra (2008) señala que la edad de los padres, las relaciones que establezcan los hijos con ellos, el número de personas que viven en el hogar, la presencia de hermanos y la posición 
ordinal que ocupe el hijo entre estos, son las influencias más importantes en el desarrollo del niño. Siendo así que estos factores determinarán su temperamento, su salud y la integración familiar.

La familia es un factor importante para el desarrollo de un individuo, especialmente en la adolescencia. Siendo en esta etapa donde más crítico se vuelve el rol de ésta. Según Carrasco (2014) en esta etapa, la familia debe enfrentar diferentes cambios, los cuales, si no son superados pueden significar una desorganización para el sistema familiar. Por un lado, el adolescente querrá defender su privacidad en contraposición de los padres que querrán mantener las pautas de relación de la niñez. Por el otro, en esta etapa, los padres se encuentran en la crisis de la "edad media" en la cual reevalúan sus ambiciones y logros alcanzados y su relación de pareja, los abuelos se preparan para el retiro y los adolescentes buscan consolidar su propia identidad. Es decir, toda la familia se encamina a un sistema más individualizado lo que conlleva una alta inestabilidad de las reglas, la comunicación y roles.

Existen diferentes factores que alteran la dinámica familiar, además de la fase del ciclo vital en la cual se encuentre. Estos son los factores sociales, dentro de los cuales los más influyentes son la falta de recursos económicos, donde la incapacidad para satisfacer las necesidades de los miembros de la familia genera la pérdida de control, sentimientos de culpa e inferioridad y violencia. Según Hoffman (1995, citado por Viguer y Serra, 2008) la clase social a la que correspondas determinará tu sistema de creencias, valores y estilos de vida. Esta determina el entorno en el cual el niño se desenvolverá, los centros de salud a los que tendrá acceso, los juegos, compañeros y lugares que frecuentará.

Además, la clase social se encuentra estrechamente ligada con los estilos educativos de los padres, siendo que los padres de clase baja tienden a utilizar el poder y la fuerza en la crianza de sus hijos, mientras que los de clase media son más propensos a la disciplina democrática. (McLoyd, 1998).

Otro factor que repercute directamente en la dinámica familiar es si el padre se encuentra empleado o desempleado (entendiendo al padre como el principal soporte 
económico del hogar). Según McLoyd (1998) el padre desempleado suele deprimirse, angustiarse y mostrarse menos receptivo, lo que conlleva a que ejerza la disciplina a través de la fuerza. Como consecuencia sus hijos tienden a ser depresivos, con poca seguridad personal y una baja capacidad para hacer frente a las presiones del ambiente.

Además, Viguer y Serra (2008) señala que la clase social en la que se desenvuelvan los hijos es un aspecto que afecta directamente a la calidad del entorno familiar. Principalmente cuando el ambiente en el que se desarrollan no se encuentra dotado de las condiciones necesarias para un desarrollo óptimo (espacio físico reducido, no contar con útiles escolares necesarios y adecuados, etc.).

En Lima, estas diferencias son palpables si observamos dos tipos de colegios: uno particular de clase media-alta y un colegio público de clase baja.

Ante esta problemática, resulta relevante formularse la siguiente pregunta de investigación ¿Existirán diferencias en el nivel de disfunción familiar en adolescentes de un colegio privado y un colegio público en el distrito de La Molina?

\subsection{Justificación y relevancia}

En los últimos años podemos apreciar cómo la sociedad se ha visto en vuelta en diferentes cambios, los cuales se encuentran especialmente ligados a las transformaciones que ha sufrido el núcleo de esta: la familia. Tal como menciona grupo1dso (2011) hoy podemos observar como en el Perú existe más violencia, abusos intrafamiliares y divorcios que degeneran la sociedad e impiden que esta pueda sobreponerse de un modo natural a las dificultades, lo cual proviene estrictamente de una falta de apoyo desde el núcleo familiar. Campos (2011) refiere que en las últimas décadas (2000-2010) se ha dado un aumento del 51,52\% \% en el divorcio en las familias Peruanas. La autora hace referencia a un estudio realizado en la Universidad de Lima en el año 2004, donde se revela que los principales problemas de las parejas provienen por la falta de comunicación (35\%), seguida de los problemas económicos (24\%) y la desconfianza (12\%). Es así, que la familia ha sufrido una serie de transformaciones y por ende es de vital importancia realizar una investigación que nos 
proporcione un aproximamiento a conocer las características de las familias peruanas y por ende, aquellas alternativas de intervención.

En el presente estudio, se estudiarán las características de las familias peruanas a partir de reconocer las diferencias de dos tipos de familias de dos colegios del distrito de La Molina y específicamente las diferencias que existen entre los sectores socioeconómicos bajo (colegio público) y medio-alto (colegio privado) de este distrito. El conocimiento de este escenario permitirá tener un mayor acercamiento a la realidad social y psicológica en el Perú, así como aportar con una investigación de tipo descriptiva sobre el tema. Además, permitirá conocer los factores que se encuentran asociados a las diferencias que existen en los sectores socioeconómicos, tal como menciona (McLoyd, 1998) y comprender qué es lo que diferencia a cada familia y las variables que influyen en su funcionalidad.

Asimismo, cabe mencionar que contribuirá a los agentes educativos a comprender la realidad de sus instituciones y qué factores podrían ser intervenidos para hacer frente a esta problemática y de esta manera reducir los porcentajes de familias disfuncionales existentes que señala Morelos (2010).

Por último, proporcionará un panorama claro sobre aquellos aspectos familiares que se encuentran afectados, creando una disfunción familiar en cada grupo. Así como, brindar información específica del modo en que los adolescentes perciben sus familias y las estrategias que se deben llevar a cabo para intervenir en esta situación desde las aulas.

\subsection{Limitaciones}

Durante la ejecución del presente estudio se presentaron diversas limitaciones, principalmente las relacionadas a la muestra, ya que al momento de aplicar el inventario de disfunción familiar en el colegio público, no se encontraba la totalidad de alumnos que conformaban la muestra en cada sección, por el contrario, se encontró con un tercio de los alumnos en cada una, esto generó una disminución en el número de adolescentes que componen la muestra. Asimismo, luego de haber aplicado el instrumento a cuatro secciones (de un total de 6), no se permitió continuar con la aplicación, lo que también 
repercutió en el número de adolescentes que componían la muestra, la cual inicialmente estaría compuesta por 180 alumnos y que finalmente estuvo conformada por 107.

Por otro lado, cabe mencionar que los resultados que se obtienen en la presente investigación, no son determinantes, es decir, son una aproximación al tema y una parcial explicación de las variables y su relación.

\section{CAPITULO II: MARCO TEÓRICO}

\subsection{Investigaciones antecedentes}

Para el presente estudio se ha realizado una revisión bibliográfica de investigaciones antecedentes relacionadas con el tema, donde diferentes autores han investigado el constructo de Disfunción Familiar, tanto dentro de nuestro país, como en el extranjero. Estas brindan información relevante y sirven como apoyo.

\subsubsection{Antecedentes nacionales}

Cuba, Jurado, Romero y Cuba en el año 2013 investigaron las características familiares asociadas a la percepción de la calidad de vida en pobladores de un área urbanomarginal en el Distrito de Los Olivos en la ciudad de Lima y determinaron la asociación entre la funcionalidad familiar y la calidad de vida en las familias. El estudio fue de tipo transversal y descriptivo. La muestra estuvo compuesta por un total de120 familias, las cuales fueron evaluadas con el cuestionario Apgar familiar y el "Family Adaptability and Cohesion Evaluation Scales III" (FACES III) para medir la funcionalidad familiar y para medir la calidad de vida se utilizó el Índice de Calidad de Vida (Ferrans and Powers Quality of Life Index) de la Universidad de Illinois. Se obtuvo como resultados que el $75 \%$ de las familias tuvo una percepción de buena calidad de vida. El tipo más frecuente de familia fue la nuclear, el 33\% de las familias se encontraban en ciclo evolutivo seguido de familias con hijos adolescentes con $31 \%$. 
El $35 \%$ de familias tenia disfunción familiar de las cuales el 3\% era extrema. Sin embargo, no se encontró una asociación significativa entre la calidad de vida y la funcionalidad familiar.

Ccoicca (2010) en Lima - Perú estudió la relación entre el Bullying y la funcionalidad familiar en una institución educativa del distrito de Comas. La muestra estuvo compuesta por 261 estudiantes de secundaria de un colegio ubicado en Comas. La investigación fue de tipo descriptivo-correlacional, puesto que se describieron el nivel de ambas variables y luego se realizó un estudio correlacional. Se utilizaron el Auto-test de Cisneros de acoso escolar y el cuestionario de APGAR familiar para la funcionalidad familiar. Los hallazgos indicaron que existe una correlación estadísticamente significativa, negativa y débil entre Bullying y funcionalidad familiar $(-0,198, p<.01)$. Con ello, concluyeron que estas variables no tienen necesariamente una relación directa, siendo así que los niños que provienen de familias estables están más apto para enfrentar situaciones de bullying.

Arenas (2009) realizó una investigación en Lima-Perú, cuyo objetivo fue determinar la relación existente entre la funcionalidad familiar y la depresión en los adolescentes atendidos en el departamento de Psicología del Hospital Nacional Hipólito Unanue. La muestra estuvo compuesta por 63 pacientes. La investigación fue de tipo descriptiva y explicativa. Los instrumentos utilizados fueron el "Family Adaptability and Cohesion Evaluation Scales III" (FACES III) y el "Cuestionario Estructural tetradimensional" para la Depresión. Los resultados indicaron que no existe una relación significativa en la muestra entre los niveles de funcionalidad familiar y niveles de depresión.

El año 2009 Camacho, León y Mathews estudiaron el funcionamiento familiar según el modelo circumplejo de Olson en Adolescentes en la ciudad de Lima. El estudio fue de tipo descriptivo de corte transversal en una institución educativa pública en el distrito de Independencia del Cono norte de Lima. La muestra estuvo compuesta por un total de 223 adolescentes que se encontraban en un rango de edad entre 14 y 17 años, estudiantes del nivel secundario. El instrumento que se utilizó para la recolección de datos fue el "Family Adaptability and Cohesion Evaluation Scales III" (FACES III). Como resultados se obtuvo que el $54,7 \%$ de estudiantes presentó un funcionamiento familiar medio; según cohesión el 50\% presentó rango bajo y según adaptabilidad el $55,6 \%$ presentó rango alto. Se concluyó que más de la mitad de la muestra representa a 
la familia con un funcionamiento familiar no saludable y con tendencia a la disfuncionalidad, con extrema separación emocional y poco involucramiento entre sus miembros, siendo que los roles de cada miembro no son claros, causando frecuentes cambios en las reglas y las decisiones parentales.

Condori realizó una investigación el año 2002 en la ciudad de Lima titulada "Funcionamiento familiar y situaciones de crisis de adolescentes infractores y no infractores en Lima Metropolitana". La investigación fue de tipo descriptiva comparativa de carácter relacional. La muestra fue obtenida por muestreo no probabilístico de tipo intencional, con un total de 514 participantes. Los instrumentos utilizados fueron el el "Family Adaptability and Cohesion Evaluation Scales III" (FACES III) y la escala "Family crisis oriented personal scales" (F-COPES). Como resultados se obtuvo que existen diferencias significativas entre los menores infractores y no infractores en cuanto al funcionamiento familiar de sus familias y las respuestas de estas ante situaciones de crisis.

\subsubsection{Antecedentes internacionales}

Gómez-Bustamante, Castillo-Ávila y Cogollo realizaron una investigación en Colombia el año 2009 cuyo objetivo era conocer los predictores de disfunción familiar en adolescentes estudiantes de secundaria en la ciudad de Cartagena. La muestra estuvo compuesta por 1730 estudiantes que se encontraban entre 13 y 17 años de edad, de los cuales el $52 \%$ era del sexo femenino y el $48 \%$ del sexo masculino, los cuales fueron seleccionados por un muestreo probabilístico. Para medir la disfunción familiar se utilizó el cuestionario de APGAR familiar y se ajustaron los predictores mediante la regresión logística binaria. Como resultados se obtuvo que el 51,8\% de la muestra cuenta con un nivel de disfunción familiar, siendo sus predictores: los síntomas depresivos con importancia clínica, baja religiosidad, vivir con la familia no nuclear, consumo de alguna sustancia, pertenecer al estrato social bajo y tener un bajo rendimiento académico. Como conclusiones se obtuvo que los síntomas depresivos con importancia clínica, la baja religiosidad y vivir con la familia no nuclear son los principales predictores para la disfunción familiar en estudiantes adolescentes de la ciudad de Cartagena, Colombia y que es posible que esta asociación sea bidireccional. 
Moreno y Chauta realizaron una investigación en Colombia el año 2012 que tenía como objetivo conocer la relación que existe entre la funcionalidad familiar, conductas externalizadas y el rendimiento académico en un grupo de adolescentes en Bogotá. La muestra estuvo compuesta por un grupo de adolescentes (entre los 12 y 16 años de edad) de un colegio distrital de la localidad de Usaquén y sus respectivos padres y maestros. El estudio fue de tipo descriptivo. Para recoger los datos se utilizaron 3 instrumentos: la Lista de Chequeo de la Conducta Infantil de Achenbach y Edelbrock (los tres cuestionarios: el auto reporte, el de padres y el de profesores); el cuestionario de APGAR familiar y el boletín académico. Se obtuvo como resultado que la mayor parte de la muestra cuenta con un nivel de disfunción familiar moderada y un rendimiento académico medio, es decir, no existe un nivel significativo de asociación entre la funcionalidad familiar y el rendimiento académico, en otras palabras, el funcionamiento familiar no es la única variable que puede explicar los niveles de rendimiento académico.

Puentes, Enríquez, Rodríguez y Correa realizaron una investigación en el año 2012 en la cual estudiaron la influencia de la familia en la sexualidad adolescente. El objetivo fue conocer el rol que cumple la familia en la salud reproductiva y en el ámbito sexual de los adolescentes. La muestra estuvo compuesta por 128 estudiantes secundarios de Centro Habana, a los cuales se les aplicó una encuesta y luego se entrevistó a sus respectivos padres en sus hogares. Como resultados se obtuvo que el $69 \%$ de los adolescentes vive con uno de sus padres, el $52 \%$ pertenece a una familia disfuncional y el $48 \%$ a familias disfuncionales. De los adolescentes que pertenecen a una estructura disfuncional, el 100\% recibieron escasa información sobre temas sexuales por parte de sus padres. En cuanto a la comunicación, para el 57\% de los adolescentes es inadecuada y para el $82 \%$ de los padres es adecuado. El $47 \%$ de los adolescentes se encuentra altamente expuesto a sufrir daño en la reproducción, $63 \%$ de estos, son de familias disfuncionales. Como conclusión se obtuvo que la información que reciben los adolescentes sobre la sexualidad es insuficiente, así como lo son los conocimientos que los padres tienen de esta. Además, hay una inadecuada comunicación entre padres e hijos que dificulta aún más este aspecto. Por último, reconocieron que todos los 
adolescentes estaban expuestos a factores de riesgo reproductivo y que los miembros de familias disfuncionales fueron los más vulnerables.

Zuleima, Gómez, De Arco, Ruiz y Campo realizaron una investigación el año 2009, analizando la asociación entre la disfuncionalidad familiar y los síntomas depresivos en estudiantes de Colombia. Se trabajó en un colegio de un sector de estrato bajo (I). Se utilizó como marco teórico las siguientes premisas: La familia es la institución básica que influye en el desarrollo emocional y brinda los cimientos para el desarrollo social de cada uno de los integrantes. Esta, estimula y promueve el estado de salud y bienestar de sus miembros. Cómo cumpla o deje de cumplir sus funciones básicas se hablará de funcionalidad. La funcionalidad familiar juega un papel importante en el desarrollo social y psicológico de los miembros de esta. La población del estudio estuvo compuesta por 495 adolescentes de una institución educativa secundaria. Los instrumentos fueron para la identificación de síntomas depresivos se aplicó la escala Zung y para determinar la funcionalidad familia se utilizó la escala de APGAR Familiar. No se encontró asociación entre disfuncionalidad familiar y síntomas Depresivos con importancia clínica.

Viguer y Serra (2008) investigaron la relación entre la calidad del entorno familiar en la infancia y el nivel socioeconómico familiar. La muestra estuvo compuesta por 410 participantes, 185 del sexo masculino y 225 del femenino, de edades entre 3 y 10 años, que habitaban la ciudad de Valencia. Los instrumentos utilizados fueron la escala H.O.M.E (Home Observation for measurement of the enviroment) de Caldwell y Bradley (1984) para medir la calidad del entorno familiar. Este instrumento consta de 55 items valorados a través de una entrevista a la madre y una observación del hogar. Y para medir el nivel socioeconómico familiar se utilizó la escala Hollingshead, la cual otorga 5 categorías: clase alta, media alta, media, media baja y baja. Los resultados obtenidos señalan que la clase social en la que se encuentran los niños es un aspecto importante en la calidad de vida de su entorno familiar.

Zapata, et al (2007) realizaron una investigación que tuvo como objetivo: conocer la frecuencia de depresión en el adolescente y su relación con las alteraciones de la funcionalidad familiar. Por lo cual, se aplicó de manera autoadministrada un 
cuestionario a 860 adolescentes de 10 a 19 años de escuela secundaria para recabar datos demográficos, el cual fue previamente validado por un estudio piloto. Luego, se aplicó el test de Zung para detectar depresión. Y en tercer lugar se utilizó el test de APGAR familiar para evaluar disfunción familiar. Luego del análisis de datos, más de la mitad de los encuestados fue diagnosticado con disfunción familiar, a pesar de esto, no se encontró una relación estadísticamente significativa con la depresión.

Jiménez-Leyva, Hernández-Juárez, Nava-Jiménez y López-Gaona (2006) estudiaron la frecuencia de depresión y disfunción familiar en adolescentes. Se utilizó como marco teórico las siguientes premisas: Los factores causales de la depresión en el adolescente son múltiples, entre ellos el genético, ya que se ha demostrado mayor riesgo de depresión en hijos de personas que presentan trastornos afectivos. Los factores sociales como la familia, la escuela, los compañeros y las relaciones sociales también desempeñan un papel importante en la génesis de la depresión del adolescente. Respecto a la interacción padre e hijo, las alteraciones más frecuentes en los adolescentes deprimidos son el carácter autoritario o permisivo de los padres, la ruptura de lazos familiares, la riña continua de los padres, el rechazo de los padres y la falta de comunicación. (p. 226). Fue un estudio observacional, prospectivo y transversal. Con una muestra de 215 adolescentes entre 15 a 19 años. Se utilizaron dos instrumentos, de los cuales, Función familiar: capacidad del sistema familiar para enfrentar y superar cada una de las para evaluar la función familiar se utilizó Family Adaptability and Cohesion Evaluation Scales III (FACES III) en su versión al español, que consta de 20 reactivos (10 de cohesión familiar y 10 de adaptabilidad familiar) Y para medir la depresión se utilizó la escala de Birleson en su versión al español. Se obtuvo como resultado que los adolescentes con depresión tenían una mayor frecuencia de familia rígidamente dispersa $(p<.05, \mathrm{OR}=6.3)$. En los adolescentes sin depresión fueron más comunes las familias flexiblemente aglutinadas $(p<.05$, OR $=0.215)$, las estructuralmente aglutinadas $(p<.05, \mathrm{OR}=0.215)$ y las rígidamente aglutinadas $(p<$ $.05, \mathrm{OR}=0.106)$. 


\subsection{Marco teórico conceptual}

A continuación se hará una revisión de los principales conceptos relacionados a la funcionalidad familiar y a la etapa de ciclo vital (adolescencia), así como las variables intervinientes en la relación de ambos. El modelo teórico en referencia es el sistémico, otorgando una mirada integral al grupo familiar y cómo sus miembros pueden interrelacionarse ocasionando cambios en el sistema. Es decir, como una disfunción familiar podría explicarse en términos de dificultades en las relaciones, roles y comunicación entre los miembros.

\subsubsection{La familia}

La familia es un grupo de personas unidas por vínculos de parentesco, ya sea consanguíneo, por matrimonio o adopción, que viven juntos por un período indefinido de tiempo y constituye la unidad básica de la sociedad (Meléndez, 2008).

Es en esta donde se satisfacen las necesidades básicas y elementales de todo individuo. Además, es el espacio en el cual se brinda amor, cariño, protección y se prepara a los hijos para la vida adulta, y su integración en la sociedad. Su finalidad por excelencia es la multiplicación, es decir, generar nuevos individuos en sociedad. Sin embargo, cumple con otras funciones básicas, como son las siguientes:

- Nutritiva: la familia se encarga de la satisfacción de necesidades básicas, aquellas que son necesarias para la supervivencia de sus miembros.

- Normativas: Tiene también la misión de forjar y crear hábitos, reglas, normas, valores en sus miembros.

\subsubsection{La familia como sistema}

Un sistema se entiende como un conjunto de partes que funcionan como una sola entidad, donde los elementos que lo componen están en interacción dinámica, de tal manera que el estado de cada uno se determina por el estado de los demás. Existen 
sistemas cerrados y abiertos. Los primeros lo son cuando no intercambian energía o información con su entorno, los segundos, sí, de tal modo que es modificado por su ambiente y este también lo modifica al mismo tiempo (Botella \& Vilaregut, 2012).

El principal sistema de la sociedad es la familia. En esta se encuentran las partes: padre, madre e hijos que funcionan como una sola entidad, en ella se cumplen todas las propiedades anteriormente señaladas.

Cusinato (1992) indica que:

En todo sistema, incluida la familia, existe un cierto grado de totalidad. Efectivamente, hay una relación entre las partes que lo forman, de manera que cualquier cambio en una parte provoca una modificación del estado interno de las otras y en todo el sistema (p. 238).

Malagoli-Togliatti (1983, citado por Cusinato, 1992) señala que:

Se considera la familia como el sistema relacional primario en el proceso de individualización, crecimiento y cambio del individuo, considerado en el seno de proceso de individualización, crecimiento y cambio de todo el sistema familiar. Cabe considerar el sufrimiento del individuo como expresión de la disfuncionalidad de todo sistema, ya sea en sus relaciones internas o con el ambiente exterior (p. 238).

En ese sentido, estaríamos hablando de un sistema, la familia, en el cual si una parte sufre un cambio, este se verá en toda la familia y no solo una.

Tal como menciona Herrera (1997) El vínculo entre los miembros de una familia es tan estrecho que el cambio en alguno de sus integrantes provoca una modificación en el resto y en consecuencia en toda la familia.

\subsubsection{Rol de los padres}

Al ser el padre y la madre elementos básicos de la familia, esto nos lleva a pensar que si una familia tiene una organización adecuada, es gracias a ellos, pero si dicha 
organización estuviera desorganizada, ellos serían también responsables (Condori, 2002).

Es por esto que se puede decir que son los padres quienes cumplen un rol fundamental en la formación, crecimiento y organización de la familia. Siendo así que estos deben dar las bases a sus hijos para que puedan afrontar y ser flexibles ante situaciones de desorganización. Winnicott (2006) señala que pueden surgir problemas en el matrimonio y que los niños pueden estar en condiciones de adaptarse a esta desintegración familiar, ya que los padres pueden guiarlos de manera satisfactoria.

\subsection{La Madre en el desarrollo}

Dentro de este proceso de desarrollo, se suele destacar el rol que cumple la madre del individuo, puesto que es la madre quien mantiene el primer contacto, quien enseña al niño a relacionarse con el medio, a sentirse seguro, querido y amado antes que nadie.

Según el psicoanalista Winnicott (2006)

La preocupación materna primaria es aquello que permite el vínculo especial de la madre con el hijo, de tal manera que es esta quien sabe qué es lo que necesita, cómo se siente, más que los médicos. (p. 29)

Es importante señalar que el desarrollo que presentará el niño dependerá en gran medida de la relación que este mantendrá con la madre y si esta le transmitirá seguridad y lo ayudará a crear su propia identidad.

La función de una madre en las primeras etapas de vida supone: sostenimiento, manipulación y presentación de objetos. En el proceso de cumplir estas, el niño establece la identificación con la madre. Si esta y la "preocupación materna primaria" es buena, se inicia un proceso de desarrollo personal y real, si por el contrario, no lo es, el niño se convierte en un conjunto de reacciones frente a los choques, y el verdadero self del niño no llega a formarse o queda oculto tras un falso self que se somete a los golpes del mundo y en general trata de evitarlos (Winnicott, 2006). 
Cuando la pareja madre-bebe funciona bien el yo del niño es muy fuerte porque está consolidado en todos los aspectos. Cuando el apoyo de la madre no existe o es el niño quien no puede desarrollarse en forma personal genera que el desarrollo este condicionado a las reacciones frente a las fallas ambientales.

\subsection{El padre en el desarrollo}

Según Morales (2010) citado en la revista "Buena salud", "el rol del padre es modelar y ser la base sólida de la familia, el que otorga la seguridad. Por lo tanto, su rol es el de vincular a su hijo con el mundo externo y enseñarle a socializar con este, enseñándole lo novedoso".

Además, explica que si bien la madre también cumple un rol socializador, es el padre quien es el principal encargado de esta misión y la madre posee un vínculo más hogareño y del mundo familiar a diferencia del mundo externo del papá.

De este modo, el padre surge como una figura más racional asociado a su mayor vinculación con el mundo socio-cultural, a diferencia de la madre que cumple un rol más protector y emocional.

Por otro lado, según Chong (s.f.) si bien en los últimos años, la presencia del padre en la crianza de los hijos ha aumentado, sigue siendo la madre quien tiene un rol protagónico. Las familias donde la madre no trabaja, el padre pasa un cuarto del tiempo que pasa la madre con sus hijos, en cambio, aquellas familias donde la madre trabaja, el padre dedica mayor cantidad de tiempo a sus hijos (un tercio del tiempo que la madre brinda). Asimismo, señala que la madre se encarga más de la crianza mientras que el padre de la parte recreacional.

Por último, agrega:

Cuando el padre está activamente presente en la vida de los niños, favorece un sentido de seguridad en la familia y es la fuente de autoridad; distinta a la de la madre en la vida de los niños. Su participación activa en la crianza de los niños, no sólo beneficia a sus hijos, sino que da a la madre una sensación de apoyo y 
bienestar emocional que influencia de manera muy positiva en la relación de la pareja (Chong, s.f.).

\subsubsection{Ciclo vital familiar}

Existen 8 etapas en el ciclo vital de la familia según Navarro (s.f.)

- Formación de la pareja: En esta etapa se encuentra el noviazgo y la elección de la pareja, consolidación y el incremento de la intimidad emocional, sexual y la adaptación a la vida en común. En esta la tarea es asumir un rol de marido y mujer y formar una identidad de pareja.

- Familia con hijos (crianza inicial): En esta se presenta un cambio de roles de esposos a padres, la organización familiar cambia, hay un desarrollo de vínculo más cercano de la madre con el hijo y la relación de pareja se reajusta de acuerdo a nuevos límites de intimidad. Principal crisis: el cambio de identidad en la madre y la depresión post-parto afectan a la inclusión del padre y la falta de intimidad.

- Familia con hijos preescolares: en esta etapa hay un cambio en los hijos, quienes pasan de ser dependientes absolutos a una dependencia relativa. Se debe decidir el estilo de crianza y formar acuerdos entre los padres. Las principales crisis se dan por: la distribución del tiempo entre el ámbito laboral y familiar, la decisión de cuantos hijos tener, la falta de intimidad y el manejo conductual de sus hijos (control de rabietas por ejemplo).

- Familia con hijos escolares (en primaria): en esta etapa los padres comienza a sentir que la eficiencia de su estilo de crianza es evaluado por el colegio y la sociedad. La pareja se adecua y retorna a sus actividades anteriores. Principales crisis: distanciamiento del hijo con la familia por inicio de sociabilización. Hay fuertes conflictos en la pareja (entre el $7 \mathrm{mo}$ y $10 \mathrm{mo}$ año de matrimonio). Empieza a ser importante el rendimiento escolar de los hijos. 
- Familia con hijos adolescentes (en secundaria): En esta etapa la familia debe mantener una comunicación abierta con los hijos, comprender y aceptar el desarrollo físico y psicológico de los hijos y que estos ya toman decisiones propias, así como aceptar que la familia está pasando por otro ciclo generacional. Las crisis de esta etapa se relacionan con el choque intergeneracional, las crisis de la adolescencia (hijos) así como las de la edad media (padres), además existe una competencia con los hijos y adaptación de su vida sexual.

- Familia como plataforma de lanzamiento: en esta etapa la pareja debe aprender a vivir sola otra vez, integrarse nuevamente y aceptar cambios propios de la vejez. Asimismo, apoyar a sus hijos a empezar su camino y aceptar nuevos roles. Las crisis se relacionan con el síndrome del nido vacío, la relación marital debe ser re-elaborada. Además cada uno debe empezar a enfrentar la soledad, jubilación y el manejo del tiempo libre.

- Familia anciana: esta etapa es muy prolongada, la pareja debe crear intereses comunes. Las crisis pueden darse por mala tolerancia a la jubilación, la aparición de enfermedades y aceptación y enfrentamiento de la muerte del cónyuge y conocidos.

\subsubsection{La adolescencia}

La adolescencia es la etapa donde se dan los mayores cambios tanto físicos como psicológicos en el individuo. Según Micucci (2009) existen tres grandes sub etapas:

\subsubsection{Adolescencia temprana (11-13 años)}

En este periodo, el adolescente se preocupa principalmente por si su cuerpo está evolucionando normalmente, ya que experimenta muchos cambios físicos. Asimismo, evidencia cambios emocionales y cognitivos, los cuales debe aprender a desempeñar de la mejor manera, tanto en el ambiente escolar como en el día a día. 
Además, empiezan a preocuparse por encontrar un lugar entre sus pares, formar parte de grupos, ser reconocidos por estos e ir de acuerdo a las tendencias que este defina para no desentonar del grupo y así no ser excluido.

Por otro lado, se inician las diferencias con los padres, pues ellos también se encuentran en una etapa de cambios en su propio ciclo vital, lo cual hace que este momento se vuelva más complejo para ambos. Es en esta etapa donde los hijos comienzan a alejarse de los padres, pedir que respeten su privacidad, dejar de compartir sus intimidades con ellos, etc.

\subsubsection{La adolescencia intermedia (14-16 años)}

En esta fase los adolescentes empiezan a lidiar con su sexualidad y las consecuencias emocionales que esto acarrea, tanto a modo personal como con sus padres. Por otro lado, empiezan a tomar sus decisiones en términos morales, creando sus propias distinciones de lo que está "bien y mal". Esta nueva manera de ver el mundo va a afectar la manera de ver a sus familias y juzgar las decisiones que toman día a día.

Esta etapa también se caracteriza por lograr un balance entre autonomía y responsabilidad. Para ellos la autonomía tiene un significado diferente del que tiene para sus padres, pues para los primeros se relaciona con tener la libertad para realizar las actividades que desean de manera libre mientras que para los segundos significa actuar con responsabilidad y disciplina asumiendo sus actos.

\subsubsection{Adolescencia tardía (17-19 años)}

En este periodo, el último de la adolescencia, el joven consolida su identidad, lo cual es uno de los grandes retos para los padres pues no saben qué rol asumir en esta etapa: si seguir siendo los padres protectores o darles la libertad para desarrollarse autónomamente. Como consecuencia de esto, se genera una disputa entre los padres e hijos, lo cual trae consecuencias como que el adolescente toma una decisión prematura 
sobre el rol que asumirá o por el contrario que haya una batalla constante sobre la autonomía del hijo.

Por otro lado, los adolescentes a esta edad comienzan a alejarse de la dependencia que poseían años anteriores y a dejar atrás esa rebeldía contra los padres por cuidar su autonomía e independencia, cambiándola por una intimidad más profunda con los adultos que los rodean, especialmente sus padres. Hay un cambio en la naturaleza de la amistad, pasando de haber una intimidad muy fuerte con los amigos a ser también una relación importante con sus padres.

Asimismo, empiezan a asumir roles dentro del hogar, asumen responsabilidades y sus padres depositan mayor confianza en ellos.

\subsubsection{Desarrollo cognitivo en la adolescencia}

Debido a que el objeto de estudio de la presente investigación es de adolescentes entre 15 y 18 años, nos centraremos en el periodo de las operaciones formales según la teoría de Piaget.

Según Inhelder \& Piaget (1955-1972, citado en Cano, 2007) la etapa de las operaciones formales se logra luego de que los adolescentes han completado la etapa anterior (operaciones concretas). En esta etapa el joven no solo se centra en aspectos observables y concretos, sino que ya puede englobar y relacionar diferentes objetos para luego emitir una opinión.

Esto le permite a su vez, plantearse hipótesis que luego someterá a prueba para confirmarlas o no. Así mismo, su pensamiento deductivo le permitirá comprender las verdaderas razones de las acciones que se han realizado en la realidad.

Es decir, son capaces de evaluar a una persona no solo por lo que realmente hace, sino también por lo que las situaciones lo llevan a actuar, es decir, tiene la habilidad de ver el potencial de las personas y sus aptitudes más allá de los hechos concretos que cometen. 


\subsubsection{Las diferencias de sexo}

Molina (2008, citado por Moreno, 2014) comenta que el sexo se caracteriza como un conjunto de representaciones, características, roles y expectativas que se asignan al hombre y a la mujer dentro de la cultura.

Romero (2011, citado por Moreno, 2014) señala que el sexo femenino ha sido asociado al ámbito más emocional y todo aquello que tiene que ver con las emociones y afectos, las relaciones interpersonales y cuidado de otros, esperando que estas se centren en brindar cuidado y mantener las relaciones íntimas.

Polo (s.f., citado por Moreno, 2014) comenta que a pesar de que a través de los años ha existido una mayor igualdad entre hombres y mujeres, la responsabilidad por el cuidado de la familia sigue siendo principalmente una preocupación y función de las mujeres.

Siendo así, que la autora concluye que las mujeres suelen estar más predispuestas a reconocer problemas de índole personal y a pedir ayuda profesional que el sexo masculino.

\subsubsection{La familia en la adolescencia}

De acuerdo a Carrasco (2014) la familia en la etapa adolescente se enfrenta a diferentes cambios de varios de sus miembros y por consecuente el funcionamiento de la misma se ve alterado. En ese sentido es una fase en la cual la homeostasis se reacomoda a un nivel de funcionamiento más adecuado según lo requerido por la familia.

En esta fase también la familia se orienta hacia el exterior y las fronteras entre los subsistemas son menos estrictas que en otras etapas, esta característica se evidencia en los conflictos que se dan entre los padres e hijos por la lucha de la autonomía, privacidad e intimidad de los adolescentes en oposición de los padres que intentan mantener los patrones de la niñez.

Para los padres esta etapa representa diversos retos, tales como: aceptar el crecimiento y desarrollo de sus hijos e ir entregándole las herramientas necesarias para que vayan forjando su intimidad y autonomía de manera adecuada. A veces, puede que las 
expectativas de los padres no sean las mismas que las de los hijos, quienes ya han desarrollado una nueva capacidad cognitiva y moral para poder tomar sus decisiones, lo cual genera conflicto entre ambos y los padres pueden asumir un rol protector y controlador.

Es frecuente que familias en otros periodos hayan sido funcionales y en esta etapa sean disfuncionales, pues es difícil aceptar los cambios, no solo de los adolescentes, sino de todos los miembros.

- Los abuelos se encuentran en la última fase del ciclo vital y se están preparando para el retiro.

- los padres se encuentran en la llamada “crisis de edad media" donde evalúan sus logros hasta el momento y los nuevos planes, asimismo, experimentan ciertos duelos por las metas que quisieran haber logrado y no pudieron.

- además hay una redefinición del subsistema parental, es decir, la pareja puede ser reevaluada, o bien hay dificultades que pueden llevar a un divorcio o la relación necesita cumplir nuevos compromisos y dejar atrás anhelos de la juventud.

- las madres se encuentran en la edad de cambios hormonales que las llevan a la menopausia, lo que altera su estado anímico y su modo de interactuar con los demás

- por último, los hijos se encuentran buscando consolidar su propia identidad e insertarse socialmente, buscando un equilibrio entre la etapa de la niñez y la nueva etapa que se avecina que es la adultez.

Es por esto, que toda la familia se vuelve más individualizada (cada uno se encuentra en un momento crítico en etapa de ciclo vital). Esto trae consigo una gran inestabilidad de las reglas, aumentan las ansiedades y los conflictos. En este momento pueden aparecer los cambios más grandes para las familias: retiros laborales, despidos, divorcios, nuevos matrimonios, nuevos medios hermanos, etc. 
Por otro lado, Harter (2005, citado por Martí, E et Onrubia, 2005), refiere que la adolescencia implica un gran proceso de transición, que se encuentra marcado de capacidades como la cognitiva y expectativas sociales que afectan el concepto de sí mismo.

Así mismo, este periodo genera un cambio drástico hacia la introspección, es decir, se vuelven más reflexivos y por ende, aquello que antes era visto como verdades incuestionables, hoy en día se transforma en hipótesis que buscan ser analizadas en la búsqueda de su identidad.

Además, la autora agrega que:

"La individuación no implica tensión y confusión. Antes bien, significa abandonar la dependencia infantil de los progenitores en favor de unas relaciones más maduras, más responsables y menos dependientes. Los adolescentes que han logrado establecer un sentido de individuación pueden aceptar la responsabilidad de sus elecciones y acciones, en lugar de buscar a sus padres para que lo hagan por ellos"

Por otro lado, comenta que los adolescentes de la edad media y tardía son quienes intentan desidealizar más a sus padres, teniendo una imagen más madura de ellos.

\subsubsection{Funcionamiento familiar}

Herrera (1997) el funcionamiento familiar es un concepto que ha sido estudiado desde las últimas décadas por diferentes escuelas, llegando a concluir que no se puede hablar de funcionalidad familiar como algo estable y fijo, sino como un estado y un proceso que se ajusta continuamente, por lo tanto podemos decir que en este concepto intervienen diferentes aspectos que pueden afectarlo.

Camacho et al (2009) señala que el funcionamiento familiar tiene una gran importancia en el desarrollo del adolescente, siendo el soporte básico para su desempeño familiar e individual, el cual mide el grado de satisfacción de las funciones básicas del sistema familiar, mediante la cohesión, armonía, rol, permeabilidad, participación y adaptabilidad. 
Así, Herrera (1997) señala que los principales aspectos para medir el funcionamiento familiar son los siguientes:

1. Bienestar: definido como el cumplimiento eficaz de sus funciones básicas, como lo son el soporte económico, el proporcionar la posibilidad de tener una educación, cuidar la salud de sus miembros y proveer un espacio culturalespiritual.

2. Autonomía: permitir el desarrollo de la identidad personal y la autonomía de sus miembros evitando la dependencia excesiva entre sus miembros y la individualidad, de modo que pueda promoverse el desarrollo de todos los miembros en equivalencia.

3. Roles: que exista un sistema de reglas y roles flexibles para la solución de conflictos. Es decir, que hayan roles específicos para cada miembro que a su vez sean aceptados y claros. Es importante evitar la sobrecarga del rol en un miembro o que este cumpla diferentes roles. Es decir, respetar las jerarquías naturales de las familias (sistemas paternales y filiales) generando una complementariedad en los roles y un apoyo mutuo.

4. Comunicación: que exista comunicación clara entre las partes que componen la familia, esta debe ser clara, coherente, afectiva y constante, por lo que los miembros puedan intercambiar opiniones, emociones y llegar a acuerdos constantemente.

5. Adaptación a los cambios: que haya capacidad para adaptarse a los cambios, pues la familia funciona adecuadamente cuando es flexible y puede acostumbrarse a situaciones nuevas o responder a un cambio repentino en sus vidas. Estos pueden ser, la mudanza a otro hogar, cambio de ciclo vital en las partes, la muerte de algún miembro, que se integre un nuevo miembro a la familia, etc.

Asimismo, por otro lado, Olson realizó estudios desde finales de los años setenta, donde trató de mostrar lo aspectos más fundamentales del funcionamiento familiar, 
entendiendo que esta puede concebirse por tres variables: la cohesión, la adaptabilidad y la comunicación familiar (Polaino-Lorente \& Martínez, 1998).

\subsubsection{Cohesión familiar}

Polaino-Lorente y Martínez (1998) indica que la cohesión familiar se conforma de dos elementos, por un lado el vínculo emocional que se establece entre los miembros de una familia, y por otro lado, el nivel de autonomía que una persona tiene en su familia.

Las familias extremadamente cohesionadas (tipo: enredado) presentan conflictos, en ocasiones graves. Siendo uno de los primeros objetivos de las terapias mejorar la autonomía y la individualización de los miembros de la familia (Polaino-Lorente \& Martínez, 1998).

\subsubsection{Adaptabilidad familiar}

Polaino-Lorente y Martínez (1998) la define como la habilidad que tiene un sistema familiar para cambiar sus estructuras de poder, roles y las reglas de la relación, en respuesta al estrés que se produce ante una situación concreta, determinada por la etapa vital de toda la familia.

\subsubsection{Comunicación familiar}

La comunicación positiva facilita a las familias el intercambio de sus necesidades y preferencias, y favorece sus modos de funcionar como familia (cohesión y adaptabilidad) (Polaino-Lorente y Martínez, 1998).

Por el contrario, las habilidades negativas para la comunicación (doble mensaje, dobles vínculos, críticas destructivas) minimizan la habilidad de la familia para poner en común y compartir sus sentimientos $\mathrm{y}$, por tanto, restringen los posibles desplazamientos en las otras dos dimensiones (Polaino-Lorente \& Martínez, 1998). 


\subsubsection{Familia disfuncional}

De este modo, llamaríamos a una familia disfuncional como un patrón de conductas desadaptativas e indeterminadas que presentan, de manera permanente, uno o varios integrantes de una familia y que al relacionarse con su membrecía se genera un clima propicio para el surgimiento de patologías específicas o inespecíficas (Vargas y Vacca, 1998)

Y se caracterizaría por el no cumplimiento de lo anteriormente señalado (Herrera, 1997) es decir:

1. No hay bienestar: no existe un apoyo económico necesario para que el individuo pueda desarrollarse, estudiar, ni cuidar la salud de los miembros.

2. No hay una autonomía clara en las partes que la componen, siendo estas o excesivamente dependientes de la opinión del resto de la familia o de necesitar autorización para realizar lo que desee, o bien una independencia total donde no hay un interés por lo que los demás que forman la familia opinen sobre él o sus quehaceres.

3. Que los roles y las reglas sean rígidos, sin capacidad de modificarse ante situaciones que lo requieran o que sean poco claros, es decir, que un mismo miembro cumpla con el rol de hijo y padre a la vez pues este último no puede asumir su rol correspondiente. O que los miembros no sepan que rol se espera que asuman debido a constantes exigencias y jerarquías distorsionadas.

4. Que la comunicación sea incoherente y poco clara, sin demostraciones afectivas a sus miembros. Es decir, la existencia de dobles mensajes o mensajes incongruentes que no llegan a ser comprendidos por los miembros.

5. Hay una incapacidad para adaptarse a situaciones nuevas, de modificar reglas y aceptar que la familia va cambiando de etapa en el ciclo vital y por ende los miembros se van yendo de casa o cambiando su modo de actuar. Así como la incapacidad para adaptarse a situaciones estresantes como muertes de algún miembros, divorcios, mudarse a otro lado, etc. 


\subsubsection{La familia peruana}

Las familias peruanas se diferencian según el lugar de procedencia e intereses, la mayoría de estas varían en cantidad de miembros que las componen y las actividades que realizan.

Según Arianli (s.f.) las familias de la costa por ejemplo, se dedican principalmente al trabajo en oficinas, tiendas o empresas (ya sean pequeñas, micro empresas o empresa grandes), además, suelen ser no muy numerosas y viven en casas o departamentos.

Según el reporte internacional del Mapa Mundial de la Familia (2013) el 24\% de los niños peruanos ha crecido con un solo progenitor, mientras que el resto cuenta con sus dos padres, esto repercute directamente en el desempeño de los niños en la prueba Pisa del 2009 donde los segundos tienen un mejor desempeño que los primeros.

Así mismo, se señala que el Perú ocupa el segundo lugar a nivel global en parejas que prefieren convivir antes que casarse. Constituyendo el primer grupo un 29\% de las parejas y las segundas un $30 \%$. Se calcula que un $73 \%$ de nacimientos ocurren fuera del matrimonio, siendo superados por Colombia.

Según Camacho et al. (2009) "en el Perú el funcionamiento familiar es preocupante desde el ámbito de la formación de la misma (tanto en la nuclear como en la extensa) se puede dar la ausencia física de uno o de los dos progenitores, implicando la falta de figuras necesarias para el desempeño vital del grupo familiar” (p.56)

Señala además, que los conflictos entre las parejas son muy comunes, así como entre padres e hijos y que también existe una marcada falta de autoridad en los padres que impide que puedan dar normas claras a sus hijos. Lo que genera desestabilización que unido a la adolescencia genera confusión en estos.

\subsubsection{Nivel socioeconómico}

Según IPSOS (2012) el nivel socioeconómico (NSE) es un grupo de personas que tienen en común condiciones económicas y sociales que las hacen similares entre sí y distintas de las demás. Se determina según las siguientes variables: el nivel y tipo de educación 
del jefe de hogar, la tenencia de bienes, el hacinamiento (miembros del hogar de acuerdo a las habitaciones disponibles) y el tipo de hogar. Asimismo, aseguran que en el caso del NSE en Lima la mayor parte de la población se encuentra en los niveles medios y el resto se encuentra en los niveles extremos (alto y bajo).

Tomando como referencia un estudio realizado por la Asociación Peruana de Empresas de Investigación de Mercados (Apeim)(2013), el distrito de La Molina, junto con el de Miraflores, San Isidro, San Borja y Surco, ocupa la zona 7, que tiene desde los niveles A (alto) hasta el nivel E (extremadamente bajo). Siendo que un $35.4 \%$ de esta población se ubica en el nivel A, un 35.9\% se localiza en el nivel B, un $21.2 \%$ se halla en el nivel C, un $5.9 \%$ se encuentra en el nivel D y un $1.6 \%$ en el nivel E.

Por otro lado, el Instituto Nacional de Estadística e Informática (INEI) (2014) refiere que se considera dentro de la categoría "pobre monetario" a aquellas personas que viven en hogares cuyo gasto per cápita es insuficiente para obtener un canasta básica de alimentos y no alimentos, es decir, vivienda, vestido, educación y salud.

Según Hoffman (1995, citado por Viguer y Serra, 2008) El nivel socioeconómico del hogar se verá relacionado con la calidad de vida de sus miembros. Refiere que la clase social está determinada por el empleo u ocupación del padre, lo cual se relaciona con las creencias, valores y estilos de vida de los subsistemas de la familia. Es la clase social la que determinará el entorno donde se desenvolverá el niño, cómo lo educarán sus padres, quien será la autoridad en el hogar, la estabilidad y por ende el tipo de educación que obtengan.

Agrega, además, que los padres tratan de manera distinta a sus hijos, dependiendo de la clase a la cual pertenecen. Así, los padres de clase media suelen mostrarse más involucrados en la vida escolar de sus hijos, asisten a reuniones de padres y se preocupan de que sus hijos estudien y obtengan buenas calificaciones. A diferencia de aquellos de clase baja, donde la mayoría de los padres suelen tener dificultades en los empleos, lo que afecta la relación con sus hijos, ya que se encuentran menos disponibles para sus hijos, se muestran más irritados, deprimidos y tensos, lo cual repercute en sus hijos, quienes se muestran desconfiados, presentan problemas de autoestima y por ende menor capacidad para enfrentar las presiones del día a día. Si bien el autor comenta que 
los problemas de empleo existen en todos los niveles socioeconómicos, suele ser el de clase obrera o baja donde más se ve este fenómeno.

\section{CAPITULO III: OBJETIVOS, HIPÓTESIS Y DEFINICIÓN DE VARIABLES}

\subsection{Objetivos}

- Analizar la diferencia del nivel de disfunción familiar en estudiantes adolescentes de quinto de secundaria de un colegio privado y un colegio público en Lima.

De este objetivo se deslindan los siguientes:

- Describir los niveles de disfunción familiar existentes en estudiantes adolescentes de quinto de secundaria de un colegio público en Lima.

- Describir los niveles de disfunción familiar en estudiantes adolescentes de quinto de secundaria de un colegio privado en Lima.

- Analizar la diferencia en los niveles de disfunción familiar en los estudiantes adolescentes de quinto de secundaria de un colegio público y un colegio privado en Lima según el sexo.

- Analizar la diferencia en los niveles de disfunción familiar en los estudiantes adolescentes de acuerdo a la presencia o no presencia de ambos padres en el hogar 


\subsection{Hipótesis}

- Existen diferencias significativas en el nivel de disfunción familiar entre los adolescentes según el colegio de procedencia.

De esta hipótesis podemos proponer las siguientes:

- Existen diferencias significativas en el nivel de disfunción familiar según el sexo de los adolescentes.

- Existen diferencias significativas en el nivel de disfunción familiar según la presencia o no presencia de ambos padres en el hogar.

\subsection{Definición de variables}

\subsubsection{Definición conceptual}

\subsubsection{Disfunción familiar:}

Patrón de conductas desadaptativas e indeterminadas que presenta de manera permanente uno o varios integrantes de una familia y que al relacionarse con su membrecía se genera un clima propicio para el surgimiento de patologías específicas o inespecíficas (Vargas \& Vacca, 1998)

Según Herrera (1997) esto está determinado por el incumplimiento de sus principales funciones: no existe un apoyo económico ni preocupación por el bienestar de los integrantes, no hay un espacio propicio para que los miembros pueden desarrollarse de manera autónoma e independiente, necesitando la opinión del otro contantemente para sentirse seguro, no se logra una claridad en los roles, es decir que los miembros no sepan qué rol se espera que asuman debido a constantes exigencias y jerarquías distorsionadas, que la comunicación sea poco clara y sin demostraciones afectivas (tanto verbal como no verbal) y por último, una incapacidad para adaptarse a las situaciones nuevas y cambiar reglas. 


\subsubsection{Nivel Socio económico:}

Según lo visto en la definición de IPSOS (2012) el nivel socioeconómico (NSE) se define como un grupo de personas que tienen en común condiciones económicas y sociales y se determina de acuerdo al nivel de estudio del jefe de hogar, los bienes que posee la familia y los miembros que viven en el hogar frente al espacio designado para cada uno.

\subsubsection{Definición operacional}

\subsubsection{Disfunción familiar}

Tomando en cuenta la definición de Herrera (1997) Familia disfuncional es aquella que:

- Bienestar: No cumple con su rol básico de proveer y velar por sus miembros tanto económicamente (dándole vestimenta, educación, alimentación) y salud (ofreciéndole la capacidad para acceder a servicios de salud)

- Autonomía: No permite desarrollo de identidad y autonomía de cada individuo, provocando una dependencia o independencia excesiva en sus miembros.

- Roles: Los roles no son claros o son invertidos, es decir los miembros no saben lo que se espera de ellos ni conocen cuál es la jerarquía en la familia.

- Comunicación: Los mensajes de los miembros no son claros o congruentes ni afectuosos, la comunicación incluye dobles mensajes (mensajes contradictorios) o no hay presencia de comunicación entre los miembros.

- Adaptación: La familia no se adapta a los cambios, es decir, le cuesta aceptar una situación nueva, comprender los cambios del ciclo vital o algún suceso importante en la familia.

\subsubsection{Nivel Socio económico:}

- Nivel socioeconómico bajo: corresponder al colegio de carácter público.

- Nivel socioeconómico medio-alto: corresponder al colegio de carácter privado. 


\section{CAPITULO IV: METODO}

4.1 Tipo y diseño de investigación

La investigación es de tipo cuantitativa y descriptiva. Puesto que utiliza la recolección de datos para probar hipótesis en base a la medición el nivel o grado de ambas variables para caracterizar la unidad de análisis (Hernández, Fernández \& Baptista 2006).

El diseño del presente estudio es de tipo transversal descriptivo comparativo. Este diseño tiene como objetivo examinar la incidencia de las modalidades o niveles de una o más variables en una población. Su procedimiento se basa en reconocer la variable en un grupo de personas para así realizar la descripción de los valores que se observan (Hernández, Fernández \& Baptista 2006).

4.2 Participantes

El tipo de muestreo que se utilizó en la presente investigación es de muestreo probabilístico por conglomeración, se realizó una selección de dos muestras conglomeradas de las cuales participaron todos los miembros que conformaban la muestra. (Hernández, Fernández \& Baptista2006).

La población para la investigación consta de 214 estudiantes de V secundaria de un colegio público y un colegio privado del distrito de La Molina de ambos sexos. Quienes cumplen el rol de hijos dentro de una familia.

Los participantes del colegio público fueron 106 adolescentes (un $49.5 \%$ de la muestra total) y los del colegio privado fueron 107 (50.5\% de la población). Obteniendo, para un tamaño del efecto médium (0.50) una potencia de 0.95 .

Asimismo, 125 fueron del sexo femenino (58.4\% de la muestra) frente a 89 del masculino (41.6 \% del total). Para lo cual se obtuvo un tamaño del efecto médium (0.50) y una potencia de 0.95 . 
Los estudiantes encuestados se encuentran dentro del rango de 15 a 19 años de edad, siendo que 43 de ellos tiene 15 (20,1\% de la muestra), 127 tienen 16 años (59.3\%), 34 tienen 17 años (15.9\%), 8 tienen 18 (3.7\%) y 2 de ellos tenían 19 años (0.9\%).

Además, según la variable de agrupación "presencia de ambos o un progenitor en el hogar" es importante mencionar que 47 de los encuestados viven con ambos padres (21.9\% de la muestra) frente a 156 que viven con solo uno de ellos (72.9\%). Cabe mencionar que no todos los encuestados respondieron con quienes vivían en el hogar, por lo que estos resultados se encuentran sobre el $94.8 \%$ de la muestra total. Asimismo, se obtuvo un tamaño del efecto médium $(0.50)$ y una potencia de 0.82 .

\subsection{Técnica de recolección de datos}

El instrumento a utilizar ha sido creado por la autora de la presente investigación como parte del curso de Diseño y construcción de instrumentos Psicológicos. Este ha pasado por una fase de diseño y de evaluación En la primera fase, se aplicó a una muestra piloto y se eliminaron/ rediseñaron ciertos ítems con el fin de aumentar la confiabilidad. Luego, se sometió a un análisis de validez de constructo mediante la modalidad criterio de Jueces y por último, se realizó un análisis de confiabilidad mediante el estadístico de Cronbach.

\subsubsection{Inventario}

- Nombre: Inventario de Disfunción Familiar (IDF)

- Autor: María Jesús Escobar

- Año: 2013

- Duración: 15 minutos

- Composición: consta de 34 items con opciones de tipo Likert (5 posibles respuestas), en las cuales se evalúa 5 áreas: Cómo la familia cuida de la salud y bienestar en general, la comunicación entre los miembros de la familia si es esta clara o incongruente, la capacidad para adaptarse a diferentes situaciones o cambios dentro de la estructura familiar, la claridad en el rol que debe asumir 
cada miembro dentro de la familia y la autonomía/ distorsión de la autonomía de los miembros. Estas áreas estarían compuestas de la siguiente manera:

\section{Factor 1: Comunicación}

- Ítems: 5, 8, 10, 21, 43, 45, 46, 49, 53.

\section{Factor 2: Adaptabilidad}

- Ítems: 7, 13, 23, 26, 28, 31, 41.

\section{Factor 3: Bienestar}

- Ítems: 3, 20, 22, 42, 51.

\section{Factor 4: Autonomía}

- Ítems: 1, 17, 24, 29, 33, 38, 52

\section{Factor 5: Roles}

- Ítems: 15, 36, 39, 40, 44, 47.

\subsubsection{Confiabilidad y validez:}

\subsection{Evidencia de validez}

Se obtuvo a través del método de criterio de jueces. Participaron 5 jueces, 4 expertos en la elaboración de ítems y estructura de pruebas psicológicas y una experta en el constructo de disfunción familiar. Luego de las respectivas encuestas se modificaron 11 items y se descartaron 2.

\subsection{Confiabilidad:}

Se logró través del alfa de Cronbach, siendo este de .93 para la prueba en general. Sin embargo, al hacer un análisis por áreas, encontramos que el área de Comunicación cuenta con una confiabilidad de .90 , la de Adaptabilidad a los cambios .83, la de Autonomía .73, la de Bienestar .74 y por último, la de Roles .74.

\subsubsection{Normas de calificación:}

\section{Puntaje total: Disfunción familiar}

- 34-61 Muy bajo nivel de disfunción familiar 
- 62-89 Bajo nivel de disfunción familiar

- 90-117 Nivel Promedio de disfunción familiar

- 118-145 Alto nivel de disfunción familiar

- 146-170 Muy alto nivel de disfunción familiar

\section{Factor 1: Comunicación}

- 5-11 Muy bajo nivel de comunicación disfuncional

- 12-18 Bajo nivel de comunicación disfuncional

- 19-25 Nivel promedio de comunicación disfuncional

- 26-32 Alto nivel de comunicación disfuncional

- 33-40 Muy alto nivel de comunicación disfuncional

\section{Factor 2: Adaptabilidad}

- 5-10 Muy bajo nivel de incapacidad a la adaptación

- 11-16 Bajo nivel de incapacidad a la adaptación

- 17-22 Nivel promedio de incapacidad a la adaptación

- 23-28 Alto nivel de incapacidad a la adaptación

- 29-35 Muy alto nivel de incapacidad a la adaptación

\section{Factor 3: Bienestar}

- 5-8 Muy bajo nivel de falta de bienestar

- 9-12 Bajo nivel de falta de bienestar

- 13-16 Nivel promedio de falta de bienestar

- 17-20 Alto nivel de falta de bienestar

- 21-25 Muy alto nivel de falta de bienestar

\section{Factor 4: Autonomía}

- 5-10 Muy bajo nivel de falta de Autonomía

- 11-16 Bajo nivel de falta de Autonomía

- 17-22 Nivel promedio de falta de Autonomía

- 23-28 Alto nivel de falta de Autonomía

- 29-35 Muy alto nivel de falta de Autonomía

\section{Factor 5: Roles}

- 5-9 Muy bajo nivel de poca claridad en los roles

- 10-14 Bajo nivel de poca claridad en los roles 
- 15-19 Nivel promedio de poca claridad en los roles

- 20-24 Alto nivel de poca claridad en los roles

- 25-30 Muy alto nivel de poca claridad en los roles

\subsection{Procedimiento de recolección de datos}

En primer lugar, se elaboraron dos cartas (una para cada institución educativa) dirigida a los Directores, para gestionar los permisos respectivos para la aplicación de los instrumentos psicológicos. Luego de tener la respuesta positiva por parte de ambos, se procedió a coordinar las fechas de aplicación, las sesiones, la cantidad de alumnos por sesión, etc.

En el caso del Colegio público, la aplicación fue dividida en 4 sesiones. En cada una se aplicó a un aula de aproximadamente 25 alumnos, donde la evaluadora hizo entrega de los folletos (que estaban compuestos por el consentimiento informado y la prueba IDF), luego procedió a leer junto con los alumnos el consentimiento informado y hablando del motivo del estudio y que los resultados serían utilizados con fines académicos. Posteriormente se procedió a leer las instrucciones de la prueba. La aplicación tuvo un aproximado de 15 minutos, que tras haber sido pasados, la evaluadora recogió los folletos y agradeció la participación voluntaria.

En el caso del Colegio privado, la aplicación se llevó a cabo en una sola sesión. La evaluadora explicó a cuatro maestros que se encontraban en su hora de clase al momento de la aplicación, sobre la metodología y procedimiento a seguir. Asimismo, les entregó un documento en el cual se encontraba las indicaciones exactas que debían otorgarle a los alumnos. La aplicación fue simultánea en cuatro aulas, por lo cual la evaluadora, fue supervisando de aula en aula la aplicación y resolviendo las dudas que surgieron por parte de los alumnos. El procedimiento de evaluación fue el mismo que en el colegio público, se entregaron los folletos, el evaluador leyó el consentimiento informado y luego de que este fue firmado, se procedió a leer las instrucciones de la prueba IDF. Habiendo trascurrido unos 15 minutos aproximadamente, se procedió a recoger los folletos completos.

A continuación se procedió a vaciar los datos de las pruebas de ambos colegios en el programa estadístico SPSS 22. Posteriormente, se realizaron obtuvieron los datos de la 
muestra y los resultados de la prueba psicológica por Colegio. Posteriormente se continuó con el análisis de los resultados, la discusión, conclusiones y recomendaciones de la investigación.

\subsection{Procesamiento y análisis de datos}

Para el procesamiento de datos de las pruebas aplicadas se utilizó el programa Statistical Package for the Social Sciences (SPSS 22). Programa estadístico que permite procesar y analizar los diferentes datos que se obtienen en las pruebas, en variables estadísticas, correlación de datos, gráfico de resultados, entre otros.

Para conocer la manera en que los datos estaban distribuidos (si contaban con distribución normal o no) se utilizó el test de Kolmogorov-Smirnov, el cual nos permite saber si la muestra se ajusta o no a la distribución esperada. Se utilizó dicho estadístico puesto que es el más apropiado para muestras mayores a 30 casos. Esta prueba nos permitió saber que en todos los casos, cuando presentábamos los datos de manera conjunta, se obtenía una distribución no normal.

Si bien algunas de las muestran sí presentaban una distribución normal, otras no lo hacían, por lo que; tomando en cuenta lo mencionado por Wackerly, Mendenhall, \& Scheaffer (2008) quienes comentaron que cuando un investigador se encuentra ante esa realidad, no puede utilizar las pruebas paramétricas, sino, las no paramétricas, que a menudo son más capaces de detectar las diferencias en las poblaciones cuando estas tienen diferentes distribuciones que las paramétricas, se decidió utilizar las pruebas no paramétricas.

En este caso se utilizó la prueba U-man Whitney, la cual según Lund \& Lund (s.f) se utiliza para comparar dos muestras independientes, donde la variable dependiente es ordinal o continua pero no presenta una distribución normal.

Y el programa G-power 3 (Cardenas, 2014) para obtener el tamaño del efecto y la potencia lograda para la muestra tanto en el caso de ambos colegios (público y privado), ambos sexos (femenino y masculino) y para la presencia o ausencia de padres en el hogar (ambos o solo uno). 


\section{CAPITULO V: RESULTADOS}

Análisis Psicométrico de la Escala IDF (Inventario de Disfunción Familiar)

Tabla 5.1

Estimación de la confiabilidad del factorl: Comunicación

\begin{tabular}{lcccc}
\hline & $M$ & $D S$ & $\begin{array}{c}\text { Correlación } \\
\text { elemento- } \\
\text { total } \\
\text { corregida }\end{array}$ & $\begin{array}{c}\text { Alfa de } \\
\text { Cronbach }\end{array}$ \\
\hline 5 & 18.69 & 7.716 & .79 & .88 \\
21 & 18.54 & 7.716 & .64 & .89 \\
49 & 18.98 & 7.716 & .7 & .89 \\
53 & 18.96 & & .74 & .89 \\
43 & 18.72 & & .72 & .89 \\
10 & 18.68 & & .73 & .89 \\
46 & 18.78 & & .64 & .89 \\
8 & 18.69 & & .56 & .90 \\
45 & 18.52 & & .55 & .90
\end{tabular}

Nota: $N=214$

Alfa de Cronbach $=.90$

En la tabla 5.1 podemos apreciar un alfa de cronbach de .90 , lo cual nos permite otorgarle fiabilidad al factor 1 . 
Tabla 5.2

Estimación de la confiabilidad del factor 2: Adaptación

\begin{tabular}{lcccc}
\hline & $M$ & $D S$ & $\begin{array}{c}\text { Correlación } \\
\text { elemento- } \\
\text { total } \\
\text { corregida }\end{array}$ & $\begin{array}{c}\text { Alfa de } \\
\text { Cronbach }\end{array}$ \\
\hline 23 & 17.64 & 19.90 & .72 & .79 \\
13 & 17.52 & 19.26 & .71 & .79 \\
26 & 17.23 & 20.57 & .65 & .80 \\
7 & 17.30 & 20.75 & .59 & .81 \\
41 & 17.50 & 20.95 & .57 & .82 \\
31 & 17.26 & 23.53 & .37 & .84 \\
28 & 17.35 & 21.55 & .48 & .83 \\
\hline & Alfa de Cronbach=.84 & \\
\hline
\end{tabular}

Nota: $N=214$

En la tabla 5.2 podemos apreciar un alfa de cronbach de .84 , lo cual nos permite otorgarle fiabilidad al factor 2.

Tabla 5.3

Estimación de la confiabilidad del factor 3: Bienestar

\begin{tabular}{lcccc}
\hline & $M$ & $D S$ & $\begin{array}{c}\text { Correlación } \\
\text { elemento-total } \\
\text { corregida }\end{array}$ & $\begin{array}{c}\text { Alfa de } \\
\text { Cronbach }\end{array}$ \\
\hline 42 & 10.14 & 8.66 & .58 & .66 \\
20 & 10.14 & 8.43 & .58 & .66 \\
3 & 9.66 & 8.83 & .45 & .71 \\
51 & 10.07 & 8.76 & .53 & .68 \\
22 & 10.06 & 10.01 & .35 & .74 \\
\hline \multicolumn{5}{c}{ Alfa de Cronbach $=.74$} \\
\hline
\end{tabular}

Nota: $N=214$ 
En la tabla 5.3 podemos apreciar un alfa de cronbach de .74, lo cual nos permite otorgarle fiabilidad al factor 3, pues un nivel de fiabilidad bastante cercano al del .80 .

Tabla 5.4

Estimación de la confiabilidad del factor 4: Autonomía

\begin{tabular}{lcccc}
\hline Ítems & $M$ & $D S$ & $\begin{array}{c}\text { Correlación } \\
\text { elemento- } \\
\text { total } \\
\text { corregida }\end{array}$ & $\begin{array}{c}\text { Alfa de } \\
\text { Cronbach }\end{array}$ \\
\hline 24 & 11.73 & 11.78 & .53 & .69 \\
29 & 11.73 & 1199 & .48 & .71 \\
17 & 12.28 & 12.20 & .52 & .7 \\
33 & 11.58 & 11.69 & .5 & .70 \\
52 & 11.79 & 12.40 & .41 & .72 \\
38 & 12.32 & 11.99 & .49 & .70 \\
1 & 12.29 & 14.11 & .27 & .75 \\
\hline
\end{tabular}

Nota: $N=214$

En la tabla 5.4 podemos apreciar un alfa de cronbach de .74 , lo cual nos permite otorgarle fiabilidad al factor 4 , pues un nivel de fiabilidad bastante cercano al del .80 . 
Tabla 5.5

Estimación de la confiabilidad del factor 5: Rol

\begin{tabular}{lcccc}
\hline Ítem & $M$ & $D S$ & $\begin{array}{c}\text { Correlación } \\
\text { elemento- } \\
\text { total } \\
\text { corregida }\end{array}$ & $\begin{array}{c}\text { Alfa de } \\
\text { Cronbach }\end{array}$ \\
\hline 36 & 12.51 & 12.66 & .46 & .72 \\
39 & 12.05 & 11.93 & .48 & .71 \\
40 & 12.55 & 13.31 & .43 & .72 \\
44 & 12.14 & 11.86 & .58 & .68 \\
47 & 12.13 & 11.9 & .56 & .69 \\
15 & 12.38 & 12.52 & .40 & .73 \\
\hline
\end{tabular}

Nota: $N=214$

Alfa de Cronbach $=.75$

En la tabla 5.5 podemos apreciar un alfa de cronbach de .75 , lo cual nos permite otorgarle fiabilidad al factor 5, pues un nivel de fiabilidad bastante cercano al del .80 . 
Tabla 5.6

Evidencia de la validez de constructo de la Escala IDF a través del análisis factorial exploratorio.

\begin{tabular}{|c|c|c|c|c|c|}
\hline \multirow{2}{*}{ Ítem } & \multicolumn{5}{|c|}{ Componente } \\
\hline & 1 & 2 & 3 & 4 & 5 \\
\hline 5 & .80 & & & & \\
\hline 21 & .77 & & & & \\
\hline 49 & .77 & & & & \\
\hline 53 & .74 & & & & \\
\hline 43 & .73 & & & & \\
\hline 10 & .71 & & & & \\
\hline 46 & .65 & & & .30 & \\
\hline 8 & .52 & & & & \\
\hline 45 & .48 & & .41 & & \\
\hline 23 & & .80 & & & \\
\hline 13 & & .77 & & & \\
\hline 26 & & .71 & & & \\
\hline 7 & & .71 & & & \\
\hline 41 & & .63 & & & .33 \\
\hline 31 & & .43 & & & \\
\hline 28 & & .41 & & & \\
\hline 42 & & & .72 & & \\
\hline 20 & & & .70 & & \\
\hline 3 & & & .65 & & \\
\hline 51 & & & .64 & & \\
\hline 22 & & & .56 & & .37 \\
\hline 24 & & & & .65 & \\
\hline 29 & & & & .64 & .31 \\
\hline 17 & .39 & & & .57 & \\
\hline 33 & & .39 & & .56 & \\
\hline 52 & & .33 & & .54 & \\
\hline 38 & .45 & & & .49 & \\
\hline 1 & & & & .46 & \\
\hline 36 & & & & & .68 \\
\hline 44 & .42 & & & & .6 \\
\hline 47 & .37 & & & & .56 \\
\hline 15 & & & .39 & & .5 \\
\hline 39 & .40 & & .32 & & .43 \\
\hline 40 & & & & & .4 \\
\hline
\end{tabular}


En la tabla 5.6 se puede observar la validez de constructo de la prueba IDF, donde se aprecian los 5 factores con sus respectivos ítems.

Tabla 5.7

Prueba K-S de bondad de ajuste a la curva normal del IDF de acuerdo al tipo de colegio

\section{Pruebas de normalidad}

\begin{tabular}{|c|c|c|c|c|c|c|c|}
\hline & & \multicolumn{3}{|c|}{ Kolmogorov-Smirnov ${ }^{\mathrm{a}}$} & \multicolumn{3}{|c|}{ Shapiro-Wilk } \\
\hline \multirow[b]{2}{*}{ Puntaje total } & Colegio & Estadístico & $\mathrm{gl}$ & Sig. & Estadístico & $\mathrm{gl}$ & Sig. \\
\hline & $\begin{array}{l}\text { Colegio } \\
\text { Publico }\end{array}$ & .07 & 106 & $.200^{*}$ & .99 & 106 & .64 \\
\hline & $\begin{array}{l}\text { Colegio } \\
\text { Privado }\end{array}$ & .06 & 108 & $.200^{*}$ & .99 & 108 & .65 \\
\hline Comunicación & $\begin{array}{l}\text { Colegio } \\
\text { Publico }\end{array}$ & .10 & 106 & .004 & .96 & 106 & .00 \\
\hline & $\begin{array}{l}\text { Colegio } \\
\text { Privado }\end{array}$ & .13 & 108 & .000 & .95 & 108 & .00 \\
\hline Adaptación & $\begin{array}{l}\text { Colegio } \\
\text { Publico }\end{array}$ & .08 & 106 & .094 & .98 & 106 & .22 \\
\hline & $\begin{array}{l}\text { Colegio } \\
\text { Privado }\end{array}$ & .10 & 108 & .016 & .98 & 108 & .06 \\
\hline Bienestar & $\begin{array}{l}\text { Colegio } \\
\text { Publico }\end{array}$ & .10 & 106 & .011 & .98 & 106 & .15 \\
\hline & $\begin{array}{l}\text { Colegio } \\
\text { Privado }\end{array}$ & .12 & 108 & .001 & .97 & 108 & .01 \\
\hline Autonomía & $\begin{array}{l}\text { Colegio } \\
\text { Publico }\end{array}$ & .10 & 106 & .009 & .96 & 106 & .00 \\
\hline & $\begin{array}{l}\text { Colegio } \\
\text { Privado }\end{array}$ & .12 & 108 & .001 & .95 & 108 & .00 \\
\hline Roles & $\begin{array}{l}\text { Colegio } \\
\text { Publico }\end{array}$ & .10 & 106 & .016 & .98 & 106 & .09 \\
\hline & $\begin{array}{l}\text { Colegio } \\
\text { Privado }\end{array}$ & .10 & 108 & .017 & .98 & 108 & .17 \\
\hline
\end{tabular}

*. Esto es un límite inferior de la significación verdadera.

a. Corrección de significación de Lilliefors

En la tabla 5.7 se observa que el puntaje total tanto para el colegio público $(n=106), D$ $(106)=.07, p=.2$; como para el colegio privado $(n=108), D(108)=.06, p=.2$; tiene una distribución normal. 
Sin embargo, en el factor 1 , donde el colegio público $(n=106), D(106)=.10, p=.00$ y en el colegio privado $(n=108), D(108)=.12, p=.00$ se puede observar que no existe una distribución normal.

En cuanto al factor 2, el colegio público $(\mathrm{n}=106), \mathrm{D}(106)=.08, \mathrm{p}=.09$ indicando que existe una distribución normal, mientras que para el colegio privado $(n=108)$, $\mathrm{D}(108)=.96, \mathrm{p}=.01$ donde no se muestra una distribución normal.

En el factor 3, el colegio público $(\mathrm{n}=106), \mathrm{D}(106)=.10, \mathrm{p}=.01$ y el colegio privado $(\mathrm{n}=108), \mathrm{D}(108)=.11, \mathrm{p}=.00$ evidencian que no existe una distribución normal.

Al igual que en el factor 4 donde, el colegio público $(n=106), D(106)=.10, p=.00$ y el colegio privado $(\mathrm{n}=108), \mathrm{D}(108)=.11, \mathrm{p}=.00$ exhiben una distribución no normal de los datos. Así como en el factor 5, el colegio público $(\mathrm{n}=106), \mathrm{D}(106)=.09, \mathrm{p}=.01$ y el colegio privado $(\mathrm{n}=108), \mathrm{D}(108)=.09 \mathrm{p}=.01$ exhiben una distribución no normal.

Tabla 5.8

Datos descriptivos del puntaje total y factores de la prueba IDF según el tipo de colegio

\begin{tabular}{llllcc}
\hline & Tipo de colegio & Media & DE & Asimetría & Curtosis \\
\hline Puntaje total & colegio publico & 85.60 & 19.82 & .11 & -.05 \\
& colegio privado & 78.90 & 15.84 & .24 & .10 \\
Factor 1 & colegio publico & 22.34 & 8.54 & .55 & -.42 \\
& colegio privado & 19.82 & 6.61 & .61 & -.48 \\
Factor 2 & colegio publico & 20.88 & 5.35 & -.16 & .06 \\
& colegio privado & 19.73 & 5.15 & .45 & .43 \\
Factor 3 & colegio publico & 12.87 & 3.87 & .34 & -.14 \\
& colegio privado & 12.17 & 3.33 & .49 & .39 \\
Factor 4 & colegio publico & 14.47 & 4.18 & .73 & 1.49 \\
& colegio privado & 13.44 & 3.78 & .81 & 1.19 \\
Factor 5 & colegio publico & 15.71 & 4.66 & .43 & .29 \\
& colegio privado & 13.81 & 3.26 & -.13 & -.38 \\
\hline
\end{tabular}

Nota $\mathrm{N}=$ colegio público 106 , colegio privado 108

En la tabla 5.8 se pueden apreciar los datos descriptivos para el puntaje total de disfunción familiar según el colegio de procedencia, donde se observa que el colegio público obtiene una media de $85.60(D E=19.82)$ mientras que el privado $78.90(D E=$ 15.84). Asimismo, el colegio público cuenta con una asimetría positiva de .11 y una 
curtosis negativa de -.05 a comparación del colegio privado que posee una asimetría positiva de .24 y curtosis positiva de .10 .

Si hacemos un análisis por factores, podemos apreciar que para el factor 1, el colegio público cuenta con una media de 22,34 ( $\mathrm{DE}=8,54)$ y el privado con 19,82 ( $\mathrm{DE}=6,61)$, además, el primero cuenta con una asimetría positiva de .55 y una curtosis negativa de .42 a comparación del segundo que cuenta con una asimetría positiva de .61 y una curtosis negativa de -.48. En el factor 2, el colegio público cuenta con una media de $20,88(\mathrm{DE}=5,35)$ y el privado con $19,73(\mathrm{DE}=5,15)$, además, el primero cuenta con una asimetría negativa de -.16 y una curtosis positiva de .06 a comparación del segundo que cuenta con una asimetría positiva de .45 y una curtosis positiva de .43 .

En el factor 3, el colegio público cuenta con una media de 12,87 ( $\mathrm{DE}=3.87$ ) y el privado con $12,17(\mathrm{DE}=3,33)$, además, el primero cuenta con una asimetría positiva de .34 y una curtosis negativa de -.14 a comparación del segundo que cuenta con una asimetría positiva de .49 y una curtosis positiva de .39 En el factor 4, el colegio público cuenta con una media de 14,47 (DE=4.18) y el privado con 13,44 (DE=3,78), además, el primero cuenta con una asimetría positiva de .73 y una curtosis positiva de 1.49 a comparación del segundo que cuenta con una asimetría positiva de $.81 \mathrm{y}$ una curtosis positiva de 1.18. En el factor 5, el colegio público cuenta con una media de 15,71 $(\mathrm{DE}=4,66)$ y el privado con 13,81 ( $\mathrm{DE}=3,26)$, además, el primero cuenta con una asimetría positiva de .43 y una curtosis positiva de .29 a comparación del segundo que cuenta con una asimetría negativa de -.13 y una curtosis negativa de -.38. 
Tabla 5.9

Resultados de la prueba U de Mann-Whitney según tipo de colegio de los participantes Resultados según tipo de colegio

Puntaje Comunicación Adaptación Bienestar Autonomía Roles

\begin{tabular}{lcccccc}
$\begin{array}{l}\text { U de Mann- } \\
\text { Whitney }\end{array}$ & 4.52 & 4.79 & 4.84 & 5.11 & 4.83 & 4.43 \\
& & & & & & \\
W de Wilcoxon & 10.41 & 10.68 & 10.72 & 11.00 & 10.72 & 10.32 \\
$Z$ & -2.64 & -2.05 & -1.95 & -1.345 & -1.97 & -2.86 \\
$\begin{array}{l}\text { Sig. asintótica } \\
\text { (bilateral) }\end{array}$ & .008 & .040 & .051 & .179 & .049 & .004 \\
\hline
\end{tabular}

a. Variable de agrupación: Colegio

En la tabla 5.9 se puede apreciar que para el puntaje total $(\mathrm{Z}=-2.64, \mathrm{p}=.00)$, factor 1 $(\mathrm{Z}=-2.05, \mathrm{p}=.04)$ factor $4(\mathrm{Z}=-1.96, \mathrm{p}=.049)$ y factor $5(\mathrm{Z}=-2.85, \mathrm{p}=.00)$ podemos rechazar la hipótesis nula y aceptar la hipótesis alterna, la cual nos indica que sí existen diferencias estadísticamente significativas en el colegio público y privado en esas situaciones.

En cambio en el factor $2(Z=-1.95, p=0,51)$ y factor $3(Z=-1.34, p=.17)$, aceptamos la hipótesis nula la cual nos indica que no existen diferencias estadísticamente significativas entre el colegio público y privado en esos factores. 
Tabla 5.10

Prueba K-S de bondad de ajuste a la curva normal del IDF de acuerdo al sexo

\begin{tabular}{llcrrr}
\hline \multicolumn{4}{l}{ Prueba de normalidad } & \multicolumn{3}{c}{ Kolmogorov-Smirnov $^{\mathrm{a}}$} \\
\hline \multirow{4}{*}{ Puntaje total } & Sexo & $\mathrm{D}$ & $\mathrm{Gl}$ & $\mathrm{p}$ & \\
& & .09 & 89 & .07 \\
Comunicación & Masculino & .06 & 125 & .20 \\
& Femenino & .13 & 89 & .00 \\
Adaptación & Masculino & .09 & 125 & .02 \\
& Femenino & .08 & 89 & .20 \\
Bienestar & Masculino & .09 & 125 & .01 \\
& Femenino & .10 & 89 & .03 \\
Autonomía & Masculino & .12 & 125 & .00 \\
\multirow{2}{*}{ Roles } & Femenino & .13 & 89 & .00 \\
& Masculino & .10 & 125 & .00 \\
& Femenino & .14 & 89 & .00 \\
& Masculino & .07 & 125 & .10 \\
\hline
\end{tabular}

*. Esto es un límite inferior de la significación verdadera.

En la tabla 5.10 se observa que el puntaje total tanto para el sexo masculino $(n=89), D$ $(89)=.09, p=.07$; como para el sexo femenino $(n=125), D(125)=.06, p=.2$; presenta una distribución normal.

Sin embargo, en el factor 1 , donde el sexo masculino $(n=89), D(89)=.13, p=.00$ y en el sexo femenino $(\mathrm{n}=125), \mathrm{D}(125)=.09, \mathrm{p}=.02$ se puede observar que no existe una distribución normal.

En cuanto al factor 2, el sexo masculino $(\mathrm{n}=89), \mathrm{D}(89)=.08, \mathrm{p}=.20$ indicando que existe una distribución normal, mientras que para el sexo femenino $(n=125), D(125)=.09$, $\mathrm{p}=.01$ donde no se muestra una distribución normal.

En el factor 3, el sexo masculino $(n=89), D(89)=.10, p=.03$ y el sexo femenino $(\mathrm{n}=125), \mathrm{D}(125)=.12, \mathrm{p}=.00$ evidencian que no existe una distribución normal.

Al igual que en el factor 4 donde, el sexo masculino $(n=89), D(89)=.13, p=.00$ y el sexo femenino $(\mathrm{n}=125), \mathrm{D}(125)=.10, \mathrm{p}=.00$ exhiben una distribución no normal de los datos.

Así como en el factor 5, el sexo masculino $(n=89), D(89)=.14, p=.00$ que presenta una distribución no normal mientras que en el sexo femenino $(\mathrm{n}=108), \mathrm{D}(108)=.07 \mathrm{p}=.10$ sí se exhibe una distribución normal. 
Tabla 5.11

Datos descriptivos del puntaje total y factores de la prueba IDF según el sexo de los participantes

\begin{tabular}{lccccc}
\hline & Sexo & Media & DE & Asimetría & Curtosis \\
\hline Puntaje total & Masculino & 78.26 & 17.71 & .55 & 1.19 \\
& Femenino & 85.04 & 18.07 & .09 & -.26 \\
Comunicación & Masculino & 19.22 & 7.11 & 1.10 & 1.36 \\
& Femenino & 22.38 & 7.89 & .43 & -.60 \\
Adaptación & Masculino & 19.24 & 5.22 & .19 & -.09 \\
& Femenino & 21.06 & 5.19 & .12 & .28 \\
\multirow{3}{*}{ Bienestar } & Masculino & 12.21 & 3.40 & .12 & -.37 \\
& Femenino & 12.73 & 3.77 & .58 & .19 \\
Autonomía & Masculino & 13.70 & 3.69 & .93 & 1.90 \\
& Femenino & 14.14 & 4.23 & .69 & 1.09 \\
Roles & Masculino & 14.07 & 4.35 & .91 & 1.83 \\
& Femenino & 15.24 & 3.88 & .23 & .20 \\
\hline
\end{tabular}

En la tabla 5.11 se pueden apreciar los datos descriptivos para el puntaje total de disfunción familiar según el sexo de los estudiantes, donde se observa que el sexo masculino obtiene una media de $78.26(D E=17.71)$ mientras que el femenino 85.04 $(D E=18.07)$. Asimismo, el sexo masculino cuenta con una asimetría positiva de $.55 \mathrm{y}$ una curtosis positiva de 1.19 a comparación del femenino que posee una asimetría positiva de .09 y curtosis negativa de -.26 .

Si hacemos un análisis por factores, podemos apreciar que para el factor 1, el sexo masculino cuenta con una media de 19,22 ( $\mathrm{DE}=7,11)$ y el femenino con 22,38 $(\mathrm{DE}=7,89)$, además, el primero cuenta con una asimetría positiva de 1.10 y una curtosis positiva de 1.36 a comparación del segundo que cuenta con una asimetría positiva de .46 y una curtosis negativa de -.60. En el factor 2, el sexo masculino cuenta con una media de 19,24 ( $\mathrm{DE}=5,22)$ y el femenino con 21,06 ( $\mathrm{DE}=5,19)$, además, el primero cuenta con una asimetría positiva de .19 y una curtosis negativa de - .09 a comparación del segundo que cuenta con una asimetría positiva de .12 y una curtosis positiva de 28 .

En el factor 3, el sexo masculino cuenta con una media de 12,21 ( $\mathrm{DE}=3.40)$ y el femenino con 12,73 ( $\mathrm{DE}=3,77)$, además, el primero cuenta con una asimetría positiva de .12 y una curtosis negativa de -.37 a comparación del segundo que cuenta con una 
asimetría positiva de .58 y una curtosis positiva de .19 En el factor 4 , el sexo masculino cuenta con una media de 13,70 ( $\mathrm{DE}=3.69)$ y el femenino con 14,14 ( $\mathrm{DE}=4,23)$, además, el primero cuenta con una asimetría positiva de .93 y una curtosis positiva de 1.90 a comparación del segundo que cuenta con una asimetría positiva de .69 y una curtosis positiva de 1.09. En el factor 5, el sexo masculino cuenta con una media de 14,07 ( $\mathrm{DE}=4,35)$ y el femenino con 15,24 ( $\mathrm{DE}=3,88)$, además, el primero cuenta con una asimetría positiva de .91 y una curtosis positiva de 1.83 a comparación del segundo que cuenta con una asimetría positiva de .23 y una curtosis positiva de 20 .

Tabla 5.12

Resultados de la prueba U de Mann-Whitney según tipo el sexo de los participantes

\section{Resultados según el sexo}

\begin{tabular}{lrrrrrr}
\hline & Puntaje & Comunicación & Adaptación & Bienestar & Autonomía & Rol \\
U de Mann- & 4.30 & 4.22 & 4.39 & 5.27 & 5.24 & 4.45 \\
$\begin{array}{l}\text { Whitney } \\
\text { W de Wilcoxon }\end{array}$ & 8.31 & 8.24 & 8.40 & 9.27 & 9.24 & 8.45 \\
Z & -2.81 & -3.02 & -2.62 & -.67 & -.73 & -2.50 \\
$\begin{array}{l}\text { Sig. asintótica } \\
\text { (bilateral) }\end{array}$ & .01 & .00 & .01 & .51 & .47 & .01 \\
\hline
\end{tabular}

a. Variable de agrupación: sexo

En la tabla 5.12 se puede apreciar que para el puntaje total $(\mathrm{Z}=-2.81, \mathrm{p}=.01)$, factor 1 $(\mathrm{Z}=-3.02, \mathrm{p}=.00)$ factor $2(\mathrm{Z}=-2.62, \mathrm{p}=.01)$ y factor $5(\mathrm{Z}=-2.50, \mathrm{p}=.01)$ podemos rechazar la hipótesis nula y aceptar la hipótesis alterna, la cual noes indica que sí existen diferencias estadísticamente significativas entre el sexo masculino y el sexo femenino en las percepción de disfunción familiar en la comunicación, adaptación a los cambios y los roles que ocupan en sus hogares.

En cambio en el factor $3(\mathrm{Z}=-.67, \mathrm{p}=.51)$ y factor $4(\mathrm{Z}=-.73, \mathrm{p}=.47)$, aceptamos la hipótesis nula la cual nos indica que no existen diferencias estadísticamente significativas entre el sexo masculino y femenino en cuanto a la percepción de bienestar y la autonomía en casa. 
Tabla 5.13

Prueba K-S de bondad de ajuste a la curva normal del IDF de acuerdo a la presencia de los progenitores en el hogar

\begin{tabular}{lllll}
\hline \multicolumn{5}{l}{ Pruebas de normalidad } \\
& Padres & \multicolumn{4}{l}{ Kolmogorov-Smirnov } & \\
& & Estadístico & Gl & Sig. \\
Puntaje total & ambos & .11 & 47 & .16 \\
& solo uno & .06 & 156 & .20 \\
Comunicación & ambos & .14 & 47 & .03 \\
& solo uno & .10 & 156 & .00 \\
Adaptación & Ambos & .09 & 47 & $.20^{*}$ \\
& solo uno & .08 & 156 & .01 \\
Bienestar & Ambos & .10 & 47 & $.20^{*}$ \\
& solo uno & .12 & 156 & .00 \\
Autonomía & Ambos & .15 & 47 & .01 \\
\multirow{2}{*}{ Roles } & solo uno & .10 & 156 & .00 \\
& Ambos & .11 & 47 & $.20 *$ \\
& solo uno & .08 & 156 & .02 \\
\hline
\end{tabular}

*. Esto es un límite inferior de la significación verdadera.

En la tabla 5.13 se observa que en el puntaje total, tanto para aquellos que viven con ambos padres $(n=47), D(47)=.11, p=.16$; como para los que viven con un solo padre $(n=156), D(156)=.06, p=.20 ;$ los datos siguen una distribución normal.

Sin embargo, en el factor 1, la presencia de ambos padres en el hogar $(n=47)$, $\mathrm{D}(47)=.14, \mathrm{p}=.03$ y la de uno solo $(\mathrm{n}=156), \mathrm{D}(156)=.10, \mathrm{p}=.00$ no presentan una distribución normal.

En cuanto al factor 2, cuando están presentes ambos padres $(n=47), D(47)=.09, p=.20$ indicando que existe una distribución normal, mientras que cuando solo está presente un progenitor $(\mathrm{n}=156), \mathrm{D}(156)=.96, \mathrm{p}=.01$ donde no se muestra una distribución normal.

En el factor 3, cuando están presentes ambos padres $(n=47), D(47)=.10, p=.20$ indicando que existe una distribución normal, mientras que cuando solo está presente un progenitor $(\mathrm{n}=47), \mathrm{D}(47)=.12, \mathrm{p}=.00$ evidencian que no existe una distribución normal.

$\mathrm{Al}$ igual que en el factor 4 donde, cuando existe la presencia de ambos progenitores en el hogar $(n=47), D(47)=.15, p=.01$ y cuando solo está uno de ellos $(n=156)$, $\mathrm{D}(156)=.10, \mathrm{p}=.00$ exhiben una distribución no normal de los datos. 
Por último, en el factor 5, la presencia de ambos padres en el hogar $(n=47), D(47)=.11$, $\mathrm{p}=.20$ indica que existe una distribución normal, mientras que cuando solo está presente un progenitor $(\mathrm{n}=156), \mathrm{D}(156)=.08 \mathrm{p}=.02$ no se presenta una distribución normal.

Tabla 5.14

Datos descriptivos del puntaje total y factores de la prueba IDF según la presencia de los progenitores en el hogar

\begin{tabular}{lccccc}
\hline & Padres & Media & DE & Asimetría & Curtosis \\
\hline Puntaje total & Ambos & 79.45 & 15.98 & -.00 & .28 \\
& Solo uno & 82.94 & 18.99 & .27 & .01 \\
Comunicación & Ambos & 19.53 & 6.83 & .73 & .17 \\
& Solo uno & 21.45 & 7.97 & .65 & -.23 \\
Adaptación & Ambos & 20.51 & 5.99 & .06 & -.40 \\
& Solo uno & 20.18 & 5.07 & .23 & .34 \\
Bienestar & Ambos & 12.02 & 3.22 & .29 & -.13 \\
& Solo uno & 12.62 & 3.77 & .46 & .08 \\
Autonomía & Ambos & 13.15 & 2.95 & .33 & .33 \\
& Solo uno & 14.27 & 4.31 & .72 & .98 \\
Roles & Ambos & 14,47 & 4.05 & .59 & .51 \\
& Solo uno & 14.86 & 4.22 & .44 & .81 \\
\hline
\end{tabular}

En la tabla 5.14 se pueden apreciar los datos descriptivos para el puntaje total de disfunción familiar según la presencia de los padres en el hogar, siendo que cuando ambos se encuentran se obtiene una media de $79.45(D E=15.98)$ mientras que cuando solo uno de ellos está presente, obtiene una media de $82.94(D E=18.99)$. Asimismo, los primeros cuentan con una asimetría negativa de -.00 y una curtosis positiva de .28 a comparación de los segundos que poseen una asimetría positiva de .27 y curtosis positiva de .01 .

$\mathrm{Al}$ analizar los factores, se puede apreciar que para el factor 1, la presencia de ambos padres cuenta con una media de 19,53 (DE=6,83) y la de uno solo con $21,45(\mathrm{DE}=7,97)$, además, el primero cuenta con una asimetría positiva de .73 y una curtosis positiva de .17 a comparación del segundo que cuenta con una asimetría positiva de 65 y una curtosis negativa de -.23. En el factor 2, cuando ambos padres viven en el hogar se exhibe una media de 20,51 (DE=5,99) y cuando solo uno lo hace presenta una media de 20,18 (DE=5,07), además, el primero cuenta con una asimetría positiva de .06 y una curtosis negativa de -.40 a comparación del segundo que cuenta con una asimetría positiva de .23 y una curtosis positiva de .34 . 
En el factor 3, cuando están ambos padres se presenta una media de 12,02 (DE=3.22) y cuando solo está uno, 12,62 ( $\mathrm{DE}=3,77)$, además, el primero cuenta con una asimetría positiva de .29 y una curtosis negativa de -.13 a comparación del segundo que cuenta con una asimetría positiva de .46 y una curtosis positiva de .08 . En el factor 4 , la presencia de ambos padres cuenta con una media de $13,15(\mathrm{DE}=2.95)$ y la de uno solo, con 14,27 ( $\mathrm{DE}=4,31)$, además, el primero cuenta con una asimetría positiva de .33 y una curtosis positiva de .33 a comparación del segundo que cuenta con una asimetría positiva de .72 y una curtosis positiva de .98 .

En el factor 5, ambos padres cuentan con una media de 14,47 (DE=4,05) y cuando solo está presente uno de ellos, se evidencia una media de 14,86 ( $\mathrm{DE}=4,22)$, además, el primero cuenta con una asimetría positiva de .59 y una curtosis positiva de .51 a comparación del segundo que cuenta con una asimetría positiva de .44 y una curtosis positiva de .81 .

Tabla 5.15

Resultados de la prueba U de Mann-Whitney según la presencia de los progenitores en el hogar

Resultados según la presencia de progenitores

\begin{tabular}{lrrrrrr}
\hline & Puntaje & Comunicación & Adaptación & Bienestar & Autonomía & Roles \\
U de Mann- & 3.35 & 3.21 & 3.49 & 3.39 & 3.17 & 3.41 \\
Whitney & 4.48 & 4.34 & 15.74 & 4.52 & 4.30 & 4.54 \\
W de Wilcoxon & -.88 & -1.28 & -.49 & -.79 & -1.40 & -.73 \\
Z & .38 & .20 & .62 & .43 & .16 & .47 \\
$\begin{array}{l}\text { Sig. asintótica } \\
\text { (bilateral) }\end{array}$ & & & & &
\end{tabular}

a. Variable de agrupación: padres

En la tabla 5.15 se puede apreciar que para el puntaje total $(\mathrm{Z}=-.88, \mathrm{p}=.38)$, factor $1(\mathrm{Z}=$ $-1.28, \mathrm{p}=.20)$, factor $2(\mathrm{Z}=-.49, \mathrm{p}=.62)$, factor $3(\mathrm{Z}=-.79, \mathrm{p}=.43)$, factor $4(\mathrm{Z}=-1.40$, $\mathrm{p}=.16)$ y factor $5(\mathrm{Z}=-.73, \mathrm{p}=.47)$ podemos aceptar la hipótesis nula, que nos indica que no existen diferencias estadísticamente significativas en el nivel de disfunción familiar, ni en ninguno de los factores que la componen en cuanto a la presencia de ambos padres en el hogar o cuando solo se encuentra uno de ellos. 


\section{CAPITULO VI: DISCUSION}

Según los resultados obtenidos, cabe mencionar que la hipótesis ha sido aceptada, es decir, se ha comprobado que existen diferencias significativas en el nivel de disfunción familiar según el colegio de procedencia. Siendo que el colegio de carácter público posee un mayor nivel de disfunción familiar que el colegio privado, siendo estas estadísticamente significativas. A pesar de esto, es importante resaltar que ambos colegios obtuvieron un puntaje total en la escala de disfunción familiar que los ubica en la categoría baja según las normas de calificación de la prueba IDF. En otras palabras, si bien existen diferencias según el colegio de procedencia, el nivel de disfunción familiar que evidencian ambos grupos es bajo. Estos resultados podemos relacionarlos con lo señalado por Hoffman (1995, citado por Viguer y Serra 2008) quien señala que el nivel socioeconómico en el cual se desenvuelva un hijo determinará su modo de ser y de enfrentarse a la realidad. Siendo así que como los padres de clase media a alta suelen involucrarse más con sus hijos a diferencia de los de clase baja por estar inmersos en la preocupación del ámbito laboral (más que los primeros).

En cuanto al análisis por factores, se puede observar que en cuanto al factor 1, es decir, la comunicación que existe entre los miembros del sistema familiar, existen diferencias estadísticamente significativas entre los colegios, siendo que los adolescentes del colegio público perciben en sus familias una mayor comunicación disfuncional que aquellos adolescentes del colegio privado, aunque ambos corresponden a la categoría promedio. Es importante comentar que según lo expuesto por Hoffman (1995, citado por Viguer y Serra 2008) los padres de clase media-alta suelen mostrarse más involucrados en la vida escolar de sus hijos, se preocupan más por ellos y mantienen una mejor comunicación a diferencia de los de clase obrera o baja quienes no suelen otorgarle el tiempo necesario ya que pueden manifestar sentimientos depresivos o de irritabilidad que impiden una adecuada comunicación con sus hijos. 
Por otro lado, en el factor 2, de adaptación a los cambios, se puede observar que no existen diferencias significativas entre ambos colegios (ambos ubicados en la categoría promedio), esto puede explicarse de acuerdo a la investigación realizada por Camacho, León y Mathews en el 2009, donde más del 50\% de la población estudiada evidenció una adaptación por encima al promedio, es decir, que los adolescentes podrían evidenciar esta capacidad para adaptarse a los cambios que surgen.

En cuanto al tercer factor, el área de bienestar (físico y emocional) se puede ver que no existen diferencias significativas entre ambos colegios, siendo el factor donde, la media de los puntajes obtenidos en ambos colegios, son los más similares, obteniendo un rango bajo. Esto concuerda con lo que señala Harter (2005, citado por Martí, E et Onrubia, 2005) ya que los adolescentes buscan su independencia e identidad, buscando dejar de lado la dependencia a sus padres y desarrollar relaciones más maduras y responsables, sin tener que buscarlos para que hagan las cosas por ellos o los protejan como lo hacían antes. Así mismo, este período genera un cambio drástico hacia la introspección, es decir, se vuelven más reflexivos y por ende, aquello que antes era visto como verdades incuestionables, hoy en día se transforma en hipótesis que buscan ser analizadas en la búsqueda de su identidad.

En el factor 4, el de autonomía se encontró que existen diferencias significativas entre la percepción que tienen los adolescentes del colegio público y los del colegio privado respecto a la falta de autonomía que tienen frente a su familia, amigos, y las responsabilidades que deben asumir. Siendo que el colegio público evidencia una mayor falta de autonomía que los del colegio privado. A pesar de esto, ambos evidencian un nivel bajo de autonomía distorsionada. Lo cual podría relacionarse con lo que señala Micucci (2009) quien refiere que entre la adolescencia intermedia y la tardía es donde se logra obtener un balance entre la autonomía y la responsabilidad. Además, es donde los adolescentes comienzan a alejarse de la dependencia que poseían años anteriores y a dejar atrás esa rebeldía contra los padres por cuidar su autonomía e independencia.

Por último, en el quinto factor, el de claridad de los roles que el adolescente debe asumir dentro de su hogar, se exhibe una clara diferencia en las medias obtenidas por los colegios, siendo estas estadísticamente significativas, donde el colegio público evidencia una mayor confusión en los roles que se espera que cumpla como hijo frente a 
los de colegio privado. Esto puede explicarse puesto que en Perú, muchos jóvenes que son miembros de familias de sector socioeconómico bajo, les piden apoyo a sus hijos para generar ingresos extra para la familia, es decir, trabajar luego de sus estudios, además, pueden ser quienes ocupen el lugar de los padres cuando estos están ausentes (trabajando) frente a sus hermanos menores, de esta manera, el adolescente no tiene claridad de lo que se espera de él, si lo que le corresponde es ser estudiante, trabajador, hijo, padre, etc. Mientras que en los adolescentes que son parte de un nivel socioeconómico medio-alto suelen tener una mayor claridad de lo que se espera de ellos, puesto que sus padres suelen indicarles que su principal y quizás única responsabilidad es la de ser estudiantes. Además, Camacho et al. (2009) Señala además, que los conflictos entre las parejas son muy comunes, así como entre padres e hijos y que también existe una marcada falta de autoridad en los padres que impide que puedan dar normas claras a sus hijos. Lo que genera desestabilización que unido a la adolescencia genera confusión en estos.

En cuanto a las diferencias según el sexo, se obtuvo como resultado que el sexo femenino es quien percibe un mayor nivel de disfunción familiar a diferencia del masculino, siendo estas diferencias, estadísticamente significativas. Sin embargo, en este caso, también, ambos poseen un nivel de disfunción familiar bajo. Esto se relaciona con lo señalado por Romero (2011, citado por Moreno, 2014) quien agrega que el sexo femenino se encuentra asociado al ámbito más emocional y todo aquello que tiene que ver con las emociones y afectos, es decir, son las mujeres quienes pueden percibir y se muestran más dispuestas a demostrar sus emociones a diferencia del sexo masculino.

En el factor de comunicación, adaptación a los cambios y los roles que cumplen en su hogar, también se evidencian diferencias estadísticamente significativas entre el sexo femenino y masculino, siendo que las mujeres perciben una mayor comunicación disfuncional, dificultades para adaptarse a los cambios y confusión en los roles que deben asumir dentro de su hogar, a diferencia de los varones. Esto puede explicarse por lo señalado por Polo (s.f., citado por Moreno, 2014) quien refiere que la responsabilidad por el cuidado de la familia sigue siendo principalmente una preocupación y función de las mujeres y que son las mujeres quienes suelen estar más predispuestas a reconocer problemas de índole personal y a pedir ayuda profesional que el sexo masculino. 
Sin embargo, en el área de bienestar físico y emocional y en la autonomía, no se encontraron diferencias estadísticamente significativas, siendo que tanto hombres como mujeres perciben un nivel bajo de ambos factores. Esto se relaciona con lo anteriormente mencionado respecto a las características de los adolescentes, quienes en esta etapa del desarrollo intentan desligarse de sus padres y evidenciar una mayor autonomía.

Por otro lado, se observa que tanto aquellos que viven con ambos padres como quienes viven con solo uno de ellos obtuvieron un puntaje de disfunción familiar bajo.

Asimismo, se obtuvo que no existen diferencias estadísticamente significativas en la media de los puntajes totales de ambos grupos tanto en el puntaje total de la escala como en los factores (comunicación, adaptación, bienestar, autonomía y roles, es decir, contar con la presencia de ambos padres o solo de uno de ellos no generaría diferencias significativas en la percepción de disfunción familiar. Según Condori (2002) la organización de la familia depende de los padres, quienes cumplen un rol fundamental en la formación y desarrollo de los hijos y son ellos quienes deben prepararlos para afrontar situaciones de desorganización familiar. En ese sentido, Winnicott (2006) agrega que si bien pueden surgir dificultades en el matrimonio, los hijos pueden adaptarse a estos si los padres los han guiado de manera satisfactoria. Esto podría ayudarnos a comprender cómo tanto un hogar que tiene solo un padre como el que tiene ambos padres no presentan diferencias estadísticamente significativas, pues si bien pueden presentarse dificultades en el matrimonio, si los padres han creado una base sólida donde el hijo pueda sentirse preparado para afrontar situaciones conflictivas y ser flexible ante estas, el contexto de un divorcio o separación no tendría que alterar significativamente una funcionalidad familiar.

Cabe mencionar, según los datos descriptivos de la muestra, que 47 de los encuestados viven con ambos padres y 156 con solo uno de ellos. Según el reporte internacional del Mapa Mundial de la Familia (2013) el 24\% de los niños peruanos ha crecido con un solo progenitor. Así mismo, Según Camacho et al. (2009) “en el Perú el funcionamiento familiar es preocupante desde el ámbito de la formación de la misma (tanto en la nuclear como en la extensa) se puede dar la ausencia física de uno o de los dos progenitores, implicando la falta de figuras necesarias para el desempeño vital del grupo familiar" (p.56) 
Por último, es importante comentar que los adolescentes hayan puntuado un nivel de disfunción familiar (como puntaje total) haya sido bajo puede relacionarse con la etapa de desarrollo en la que se encuentran según lo expuesto por la teoría de Inhelder \& Piaget (1955-1972, citado por Cano, 2007), ya que si bien es la etapa donde mayores cambios se presentan en la vida familiar, los adolescentes pueden percibir la realidad de una manera mucho más subjetiva de lo que lo hacían cuando eran niños, es decir, pueden reconocer y reflexionar acerca de los sucesos y darse cuenta que las personas, en este caso sus padres, pueden cometer errores y eso no es necesariamente algo que va a determinarlos como personas. 


\section{CAPITULO VII: CONCLUSIONES}

1. Existen diferencias entre el nivel de disfunción familiar en los adolescentes de quinto de secundaria de un colegio público y un colegio privado del distrito de La Molina.

2. Si bien se evidencian diferencias en el nivel de disfunción familiar en ambos colegios, estos se encuentran en un nivel bajo de disfunción familiar. Lo cual se relaciona con el hecho de que, en muchas ocasiones, los adolescentes, pesar de que en sus hogares existan dificultades, suelen evidenciar que su percepción es distinta, es decir, que pueden comprender que en sus hogares pueden existir complicaciones y que sus padres pueden cometer errores.

3. Se encontraron diferencias también en los factores de comunicación, autonomía y roles, entre los colegios, lo cual se relaciona a las diferencias que existen entre la crianza de las familias en los diferentes sectores socioeconómicos.

4. No se encontraron diferencias en los factores de bienestar y adaptación a los cambios, entre los colegios, el sexo y presencia de ambos padres en el hogar, lo cual se encuentra relacionado a las características de la muestra, es decir, la etapa donde se encuentran: la adolescencia, donde se evidencia una mayor capacidad para adaptarse a los cambios y desarrollar un bienestar sin la ayuda de sus padres.

5. Así mismo, se evidenció que es el sexo femenino quien percibe mayor disfunción familiar que el masculino así como en los factores de comunicación, adaptación a los cambios y los roles, lo cual se relaciona con las características emocionales y psicológicas del sexo que deben asumir mayores responsabilidades en el hogar a diferencia de los hombres.

6. En cuanto a la presencia de ambos o de un solo progenitor en el hogar, no se encontraron diferencias significativas en el nivel de disfunción familiar ni en 
ninguno de los factores, lo cual se puede explicar según los datos actuales que informan que hoy en día los divorcios son más comunes que antes y que estos no necesariamente genera que una familia se convierta en disfuncional, ya que si los padres han preparado bien a sus hijos para adaptarse a los cambios, ellos podrían sobrellevar esta situación. 


\section{CAPITULO VIII: RECOMENDACIONES}

- Es de vital importancia realizar una investigación con jóvenes de edades menores y poder diferenciar los resultados obtenidos, de modo que se pueda llegar a una conclusión clara sobre las diferencias que pueden tener los adolescentes frente a los niños respecto a la disfunción familiar en sus hogares.

- Para posteriores estudios, se podría comparar los resultados de la percepción de la disfunción familiar de hermanos dependiendo de la posición ordinal que ocupen y analizar estas diferencias.

- Luego de las conclusiones obtenidas, es importante generar un plan de intervención en ambos colegios, principalmente aquellos que presentan mayores dificultades en la funcionalidad familiar, es decir, los de nivel socioeconómico bajo, de modo que se pueda promover un mayor involucramiento de las familias en el desarrollo de los adolescentes. Así como promover en los estudiantes mediante dinámicas, talleres o espacios dentro de clase, una aceptación de los aspectos tanto positivos como negativos de sus familias. Además, incentivar que los adolescentes puedan tener claro aquello que se espera de ellos, que roles deben asumir en su hogar y las reglas que deben respetar.

- Por otro lado, debido a las diferencias observadas según el sexo, es de vital importancia que ambos colegios puedan ser conscientes de esta realidad para que posteriormente puedan promover una igualdad en los roles que desempeñan dentro del hogar, la comunicación y la adaptación a los cambios, desde edades tempranas.

- Asimismo, es importante mantener una promoción de un desarrollo de la autonomía desde edades tempranas, lo cual permite, según lo observado en los resultados, preparar a los adolescentes para que puedan comprender las 
situaciones conflictivas y resolverlas de manera adaptativa, en caso se presentasen.

- Con el fin de generar una mayor capacidad de adaptación a los cambios, es importante, desde las aulas, enseñarle a los jóvenes los cambios que sufren las familias desde los últimos 20 años, tanto en tasas de divorcios, familias monoparentales, familias homosexuales, etc. 


\section{REFERENCIAS}

Apeim (2013). Niveles socioeconómicos 2013. Recuperado de: http://www.apeim.com.pe/wp-content/themes/apeim/docs/nse/APEIM-NSE2013.pdf

Arenas, S. (2009). Relación entre funcionalidad familiar y la depresión en adolescentes (Tesis de Licenciatura). Universidad Nacional Mayor de San Marcos: Perú.

Recuperada

de: http://www.cybertesis.edu.pe/bitstream/cybertesis/2562/1/arenas_as.pdf

Arianli (s.f.) Las familias peruanas. [Mensaje en un blog]. Recuperado de: http://caracteristicasdelafamiliaperuana.blogspot.com/

Botella, L., \& Vilaregut, A. (2012). La perspectiva sistémica en terapia familiar: Conceptos básicos, investigación y evolución. Recuperado de: http://jmonzo.net/blogeps/terapiafamiliarsistemica.pdf

Camacho, P., León, C., \& Mathews, S. (2009). Funcionamiento familiar según el Modelo Circumplejo de Olson en adolescentes. Revista de Enfermería Herediana. (6), p. 51-58. Recuperado de:

http://www.upch.edu.pe/faenf/images/pdf/Revistas/2013/febrero/funcionamientofamili arsegunelmodelocircumplejodeolson.pdf

Campos, C. (4 de noviembre de 2011). Divorcios aumentaron hasta en más de un 50\%. La República. Recuperado de: http://larepublica.pe/04-11-2011/divorciosaumentaron-hasta-en-mas-de-50

Cardenas, M. (2014). Potencia estadística y cálculo del tamaño del efecto en G*power: complementos a las pruebas de significación estadísticas y su aplicación en 
psicología.

Recuperado

de:

http://www.saludysociedad.cl/index.php/main/article/viewFile/182/182

Carrasco, E. (2014). La familia como sistema relacional. (Curso salud y desarrollo del adolescente).

Recuperado

de

http://escuela.med.puc.cl/paginas/ops/curso/Lecciones/Leccion03/M1L3Leccion.h tml

Cano, A. (2007). Cognición en el adolescente según Piaget y Vygotski. ¿Dos caras de la misma moneda? Boletim Academia Paulista de Psicologia, 27(2), p. 148-166 Recuperado de: http://www.redalyc.org/articulo.oa?id=94627214

Ccoicca, T. (2010). Bullying y funcionalidad familiar en una institución educativa del distrito de comas (Tesis de licenciatura). Universidad Federico Villareal: Perú.

Chong, N. (s.f.) La importancia del padre. Recuperado de: www.ifasil.com

Condori, L. (2002). Funcionamiento familiar y situaciones de crisis de adolescentes infractores y no infractores en Lima Metropolitana (Tesis de Maestría).

Recuperada

de:

http://sisbib.unmsm.edu.pe/bibvirtual/tesis/salud/condori_i_l/indice.htm

Cuba, M., Jurado, A., Romero, Z., \& Cuba, M. (2013). Características familiares asociadas a la percepción de la calidad de vida en pobladores de un área urbanomarginal en el Distrito de Los Olivos, Lima. Revista de Medicina Herediana, 24, p. 12-16. Recuperado de: http://www.scielo.org.pe/pdf/rmh/v24n1/v24n1ao2.pdf

Cusinato, M. (1992). Psicología de las relaciones familiares. Barcelona: Herder.

Gómez-Bustamante, E., Castillo-Ávila, I., \& Cogollo, Z. (2009). Predictores de disfunción familiar en adolescentes escolarizados. Revista Colombiana de $\begin{array}{lll}\text { Psiquiatría, } & \text { 42(1), } & \text { p.72-80 }\end{array}$ 
http://www.scielo.org.co/scielo.php?script=sci_arttext\&pid=S0034-

74502013000100007

Grupo1dso (23 de mayo de 2011). Impacto de las familias disfuncionales en la sociedad. [Mensaje en un blog]. Recuperado de: https://cuestionessociales.wordpress.com/2011/05/23/impacto-de-las-familiasdisfuncionales-en-la-sociedad/

Hernández, R., Fernández, C., \& Baptista, P. (2006). Metodología de la investigación (4 $4^{\mathrm{a}}$ ed.). Ciudad de México: McGraw-Hill.

Herrera, P. (1997). La familia funcional y disfuncional, un indicador de salud. Revista Cubana de Medicina General Integral, 13(6), p.1-8. Recuperado de: http://docslide.net/documents/la-familia-funcional-y-disfuncional.html

INEI (2014). Una mirada a Lima Metropolitana. Recuperado de: http://www.inei.gob.pe/media/MenuRecursivo/publicaciones_digitales/Est/Lib116 8/libro.pdf

IPSOS Apoyo (2012). Niveles socioeconómicos en Lima Metropolitana. Revista Marketing. 12 (233), p. 1-3. Recuperado de: http://www.ipsos.pe/sites/default/files/marketing_data/MKT_Data_NSE_Lima_20 12.pdf

Jiménez-Leyva, R., Hernández-Juárez, A. M., Nava-Jiménez, G., \& López-Gaona, V. (2006). Depresión en adolescente y funcionamiento familiar. Revista Médica del Instituto Mexicano del Seguro Social, 45(3), 225-232. Recuperado de: http://edumed.imss.gob.mx/edumed/rev_med/pdf/gra_art/A62.pdf

Llavona, L., \& Méndez, F. (2012). Manual del Psicólogo de familia: Un nuevo perfil profesional. España: Pirámide. 
Lund, A. \& Lund, M. (s.f). Mann-Whitney U Test using SPSS. Recuperado de: https://statistics.laerd.com/spss-tutorials/mann-whitney-u-test-using-spssstatistics.php

Martí, E \& Onrubia (2005). El desarrollo de la adolescencia III. Recuperado de: https://www.academia.edu/4003046/Desarrollo_de_los_adolescentes_III

McLoyd, V. (1998). Socioeconomic disadvantage and child development. Revista Pubmed. $53(2)$, $185-204$ Recuperado

de: http://www.ncbi.nlm.nih.gov/pubmed/9491747

Meléndez, J. (2008). Necesidades que presentan los familiares de los pacientes ingresados en las áreas críticas del Hospital de Huaral. Lima, (Tesis de Licenciatura). Universidad Nacional Mayor de San Marcos: Perú. Recuperado de: http://ateneo.unmsm.edu.pe/ateneo/bitstream/123456789/3198/1/Melendez_Escal ante_Jessica.pdf

Micucci, J. (2009). The adolescent in family therapy. New york: The guilford press

Morales, R. (15 de septiembre de 2010). El rol del padre en la actualidad. Recuperado de: http://www.revistabuenasalud.com/el-rol-del-padre-en-la-actualidad/

Morelos (2010). Alarmante aumento de familias disfuncionales. El sol de cuerna vaca. Recuperado de: http://www.oem.com.mx/elsoldecuautla/notas/n1746661.htm

Moreno, J., \& Chauta, L. (2012). Funcionalidad familiar, conductas externalizadas y rendimiento académico en un grupo de adolescentes de la Ciudad de Bogotá. Psychologia. Avances de la Disciplina, 6(1), 155-166. Recuperado de: http://www.redalyc.org/articulo.oa?id=297225770006

Moreno, A. (2014) Manual de Terapia Sistémica. Principios y herramientas de intervención. Bilbao: Desclée De Brouwer. 
Navarro, D. (s.f.). Ciclo vital y la consejería familiar. Recuperado de: http://biblioteca.uns.edu.pe/saladocentes/archivoz/publicacionez/ciclo_vital_y_la_ consejer\%EDa_familiar.pdf

Polaino-Lorente, A., \& Martínez, P. (1998). Evaluación Psicológica y psicopatología de la familia. Madrid: Ilustrada.

Puentes, E., Enríquez, B., Rodríguez, Y., \& Correa, M. (2012). La sexualidad en adolescentes de la secundaria básica. Revista Cubana de Medicina General Integral, 28(4), 599-610. Recuperado de: http://scielo.sld.cu/scielo.php?pid=S0864-1252012000400004\&script=sci_arttext

Reporte Internacional Mapa Mundial de la Familia (2013). El $5 \%$ de las familias peruanas sufre de pobreza absoluta, según el Mapa Mundial de la Familia 2014 [Mensaje en un blog]. Recuperado de: http://familiaperuana.wordpress.com/

Revuelta, I., \& Alberti, R. (2008). Depresión y entorno familiar. Salud Mental, la Revista de la Salud Mental. Recuperado de http://www.saludmental.info/Secciones/psiquiatria/2008/depresion-entornofamiliar-junio08.html

Talledo, J. (2011). Perú registra una de las tasas de matrimonio más bajas del mundo. Recuperado de: http://udep.edu.pe/hoy/2011/peru-registra-una-de-las-tasas-dematrimonio-mas-bajas-del-mundo/

Vargas, J.C., \& Vacca, R. (1998). La familia funcional y disfuncional. Recuperado de: http://es.scribd.com/doc/55751513/Familia-Funcional-y-Disfuncional

Viguer, P. \& Serra, E. (2008). Nivel socioeconómico y calidad del entorno familiar en la infancia. Recuperado de: 
http://pepsic.bvsalud.org/scielo.php?script=sci_arttext\&pid=S167610492008000100007

Wackerly, D., Mendenhall, W. \& Scheaffer, R. (2008). Mathematical Statistics with Applications. Ediciones: Cengage Learning

Winnicott, D. (2006). La familia y el desarrollo del individuo. Buenos Aires: Ediciones Hormé S.A.E

Zapata, J., Figueroa-Gutiérrez, M., Méndez-Delgado, N., Miranda-Lozano, V., LinaresSegovia, B., Carrada-Bravo, T., Vela-Otero, Y., \& Rayas-Lundes, A. (2007). Depresión asociada a la disfunción familiar en la adolescencia. Artemisa en Línea, 64, 295-301. Recuperado de: http://www.medigraphic.com/pdfs/bmhim/hi2007/hi075e.pdf.

Zuleima, C., Gómez, E., De Arco, O., Ruiz, I., \& Campo-Arias, A. (2009). Asociación entre disfuncionalidad familiar y síntomas depresivos con importancia clínica en estudiantes de Cartagena, Colombia. Revista Colombiana de Psiquiatría, 38(4), 637-644.

Recuperado

de: http://redalyc.uaemex.mx/redalyc/pdf/806/80615450005.pdf 


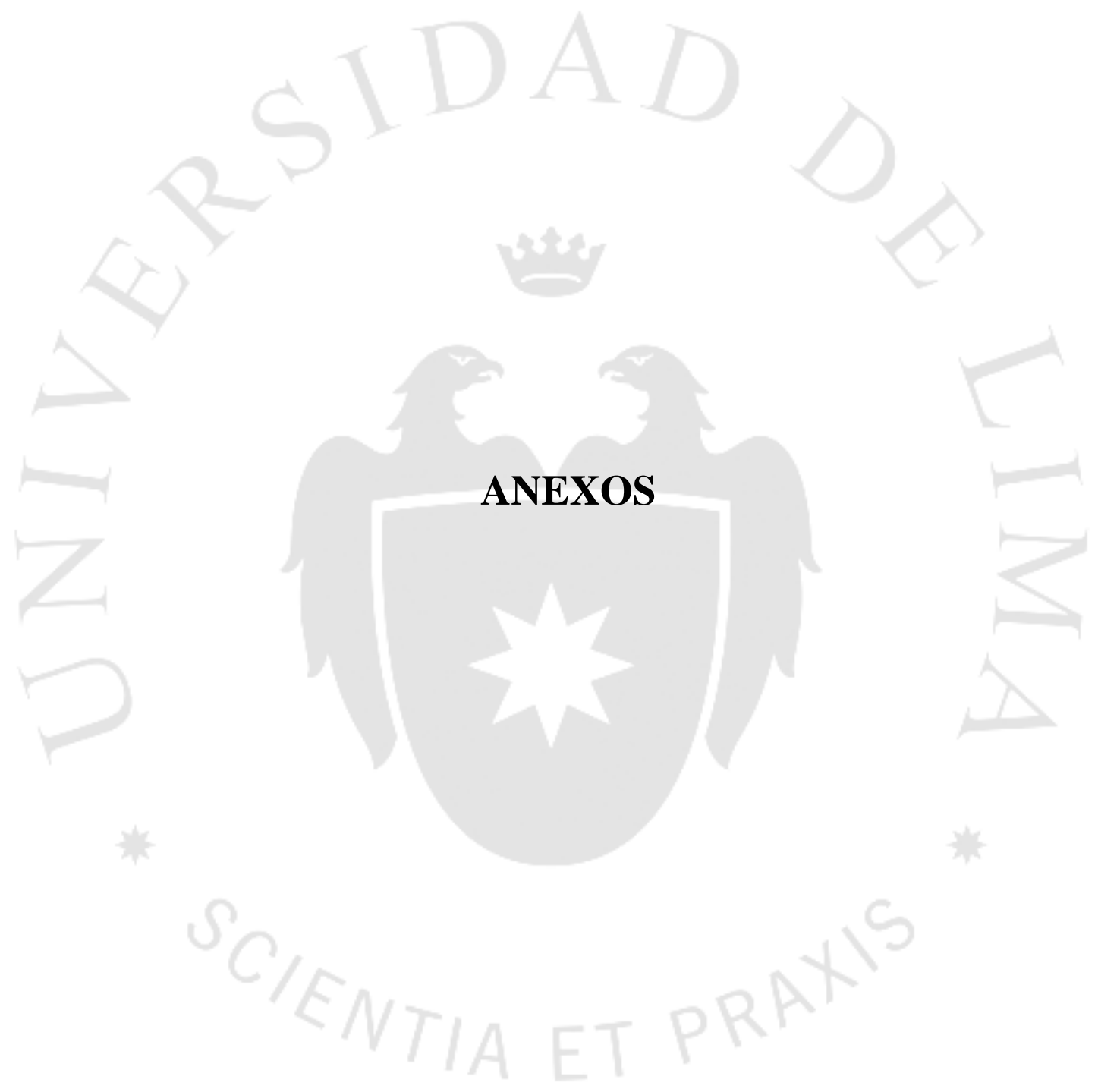




\section{ANEXO 1: FICHA TÉCNICA}

- Nombre:

Inventario de Disfunción Familiar (IDF)

- Autor:

María Jesús Escobar

- Año:

2013

- Duración:

15 minutos

Composición: consta de 34 items con opciones de tipo Likert (5 posibles respuestas), en las cuales se evalúa 5 áreas: Cómo la familia cuida de la salud y bienestar en general, la comunicación entre los miembros de la familia si es esta clara o incongruente, la capacidad para adaptarse a diferentes situaciones o cambios dentro de la estructura familiar, la claridad en el rol que debe asumir cada miembro dentro de la familia y la autonomía/ distorsión de la autonomía de los miembros. Estas áreas estarían compuestas de la siguiente manera:

\section{Factor 1: Comunicación}

- Ítems: 5, 8, 10, 21, 43, 45, 46, 49, 53.

\section{Factor 2: Adaptabilidad}

- Ítems: 7, 13, 23, 26, 28, 31, 41 .

Factor 3: Bienestar

- Ítems: 3, 20, 22, 42, 51.

\section{Factor 4: Autonomía}

- Ítems: 1, 17, 24, 29, 33, 38, 52

Factor 5: Roles

- Ítems: 15, 36, 39, 40, 44, 47. 
4.5.1.1 Normas de calificación:

Puntaje total: Disfunción familiar

- 34-61 Muy bajo nivel de disfunción familiar

- 62-89 Bajo nivel de disfunción familiar

- 90-117 Nivel Promedio de disfunción familiar

- 118-145 Alto nivel de disfunción familiar

- 146-170 Muy alto nivel de disfunción familiar

\section{Factor 1: Comunicación}

- 5-11 Muy bajo nivel de comunicación disfuncional

- 12-18 Bajo nivel de comunicación disfuncional

- 19-25 Nivel promedio de comunicación disfuncional

- 26-32 Alto nivel de comunicación disfuncional

- 33-40 Muy alto nivel de comunicación disfuncional

\section{Factor 2: Adaptabilidad}

- 5-10 Muy bajo nivel de incapacidad a la adaptación

- 11-16 Bajo nivel de incapacidad a la adaptación

- 17-22 Nivel promedio de incapacidad a la adaptación

- 23-28 Alto nivel de incapacidad a la adaptación

- 29-35 Muy alto nivel de incapacidad a la adaptación

\section{Factor 3: Bienestar}

- 5-8 Muy bajo nivel de falta de bienestar

- 9-12 Bajo nivel de falta de bienestar 
- 13-16 Nivel promedio de falta de bienestar

- 17-20 Alto nivel de falta de bienestar

- 21-25 Muy alto nivel de falta de bienestar

Factor 4: Autonomía

- 5-10 Muy bajo nivel de falta de Autonomía

- 11-16 Bajo nivel de falta de Autonomía

- 17-22 Nivel promedio de falta de Autonomía

- 23-28 Alto nivel de falta de Autonomía

- 29-35 Muy alto nivel de falta de Autonomía

\section{Factor 5: Roles}

- 5-9 Muy bajo nivel de poca claridad en los roles

- 10-14 Bajo nivel de poca claridad en los roles

- 15-19 Nivel promedio de poca claridad en los roles

- 20-24 Alto nivel de poca claridad en los roles

- 25-30 Muy alto nivel de poca claridad en los roles 
ANEXO 2: ESCALA IDF

\section{ESCALA IDF}

\section{Datos generales:}

- sexo:

- Edad:

- Año de estudios:

- Personas que viven en tu hogar:

- Posición ordinal (hermanos):

A continuación se te presenta una serie de enunciados que plantean diversos aspectos de la vida de toda persona. Deberás responder marcando con una " $X$ " en el recuadro correspondiente, qué tan de acuerdo estás con estos. Teniendo en cuenta que:

$5=$ Totalmente de acuerdo

4= De acuerdo

$3=\mathrm{Ni}$ acuerdo ni desacuerdo

$2=$ En desacuerdo

$1=$ Totalmente en desacuerdo

Ejemplo:

\begin{tabular}{|l|c|c|c|c|c|}
\hline \multicolumn{1}{|c|}{ Enunciados } & $\begin{array}{c}\text { Totalment } \\
\text { e de } \\
\text { acuerdo } \\
5\end{array}$ & $\begin{array}{c}\text { De } \\
\text { acuerdo } \\
4\end{array}$ & $\begin{array}{c}\text { Ni acuerdo ni } \\
\text { desacuerdo } \\
3\end{array}$ & $\begin{array}{c}\text { En } \\
\text { desacuerdo } \\
2\end{array}$ & $\begin{array}{c}\text { Totalmente } \\
\text { en } \\
\text { desacuerdo } \\
1\end{array}$ \\
\hline $\begin{array}{l}\text { Me parece divertido ir al cine con } \\
\text { mis amigos }\end{array}$ & & $\mathrm{X}$ & & & \\
\hline
\end{tabular}




\begin{tabular}{|c|c|c|c|c|c|}
\hline Enunciados & $\begin{array}{l}\text { Totalmente de } \\
\text { acuerdo } \\
5\end{array}$ & $\begin{array}{c}\text { De acuerdo } \\
4\end{array}$ & $\begin{array}{c}\text { Ni acuerdo } \\
\text { ni } \\
\text { desacuerdo } \\
3\end{array}$ & $\begin{array}{c}\text { En } \\
\text { desacuerdo } \\
2\end{array}$ & $\begin{array}{c}\text { Totalmente } \\
\text { en } \\
\text { desacuerdo } \\
1\end{array}$ \\
\hline $\begin{array}{l}\text { 1. Puedo hacer cosas de manera } \\
\text { independiente cuando estoy en } \\
\text { mi casa }\end{array}$ & & & & & \\
\hline $\begin{array}{l}\text { 2. Se me hace difícil decir lo que } \\
\text { pienso y quiero a los demás }\end{array}$ & & & & & \\
\hline $\begin{array}{l}\text { 3. En mi familia hay pocas } \\
\text { demostraciones de afecto }\end{array}$ & & & & & \\
\hline $\begin{array}{l}\text { 4. En mi familia, si hay algún } \\
\text { cambio, me cuesta aceptarlos }\end{array}$ & & & & & \\
\hline $\begin{array}{l}\text { 5. En mi casa es difícil mantener una } \\
\text { conversación }\end{array}$ & & & & +2 & \\
\hline $\begin{array}{l}\text { 6. En mi casa siento que recibo poco } \\
\text { afecto (demostraciones físicas y } \\
\text { verbales) }\end{array}$ & & 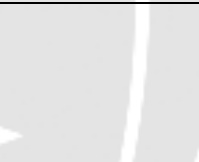 & & & \\
\hline $\begin{array}{l}\text { 7. En mi casa me cuesta } \\
\text { acostumbrarme a algún cambio }\end{array}$ & & & & & \\
\hline $\begin{array}{l}\text { 8. Me cuesta tomar mis propias } \\
\text { decisiones fuera de mi casa }\end{array}$ & & Pan & & th & \\
\hline $\begin{array}{l}\text { 9. Mi salud es algo importante para } \\
\text { mi familia }\end{array}$ & & & & & \\
\hline $\begin{array}{l}\text { 10.Me resulta difícil decir lo que } \\
\text { siento cuando estoy con mis } \\
\text { amigos }\end{array}$ & $1 / A$ & 7 & & & \\
\hline $\begin{array}{l}\text { 11. En mi casa hay muchas } \\
\text { demostraciones de afecto (física y } \\
\text { verbalmente) }\end{array}$ & & & & & \\
\hline $\begin{array}{l}\text { 12. Me es difícil entender lo que } \\
\text { debo hacer cuando estoy con mis }\end{array}$ & & & & & \\
\hline
\end{tabular}




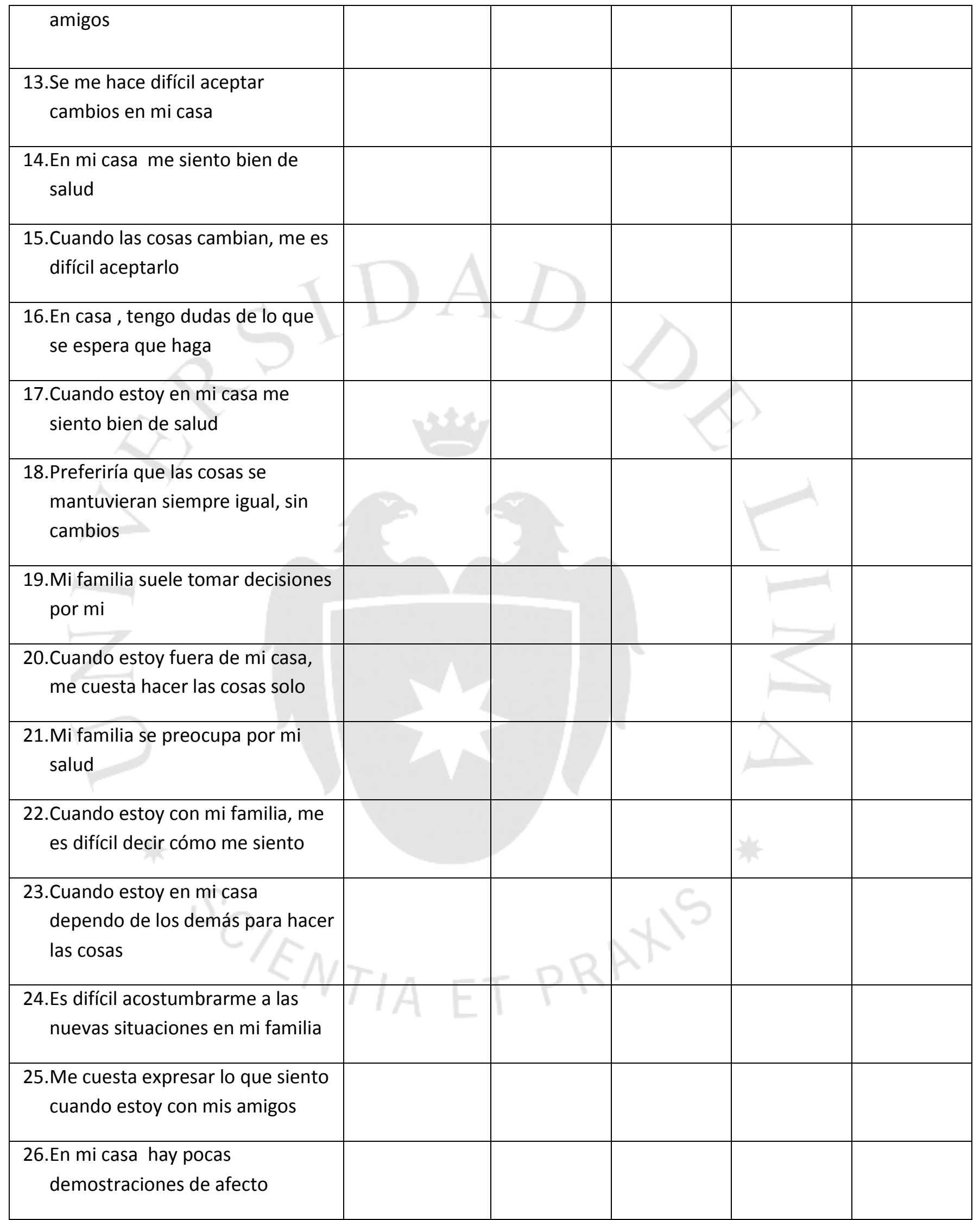




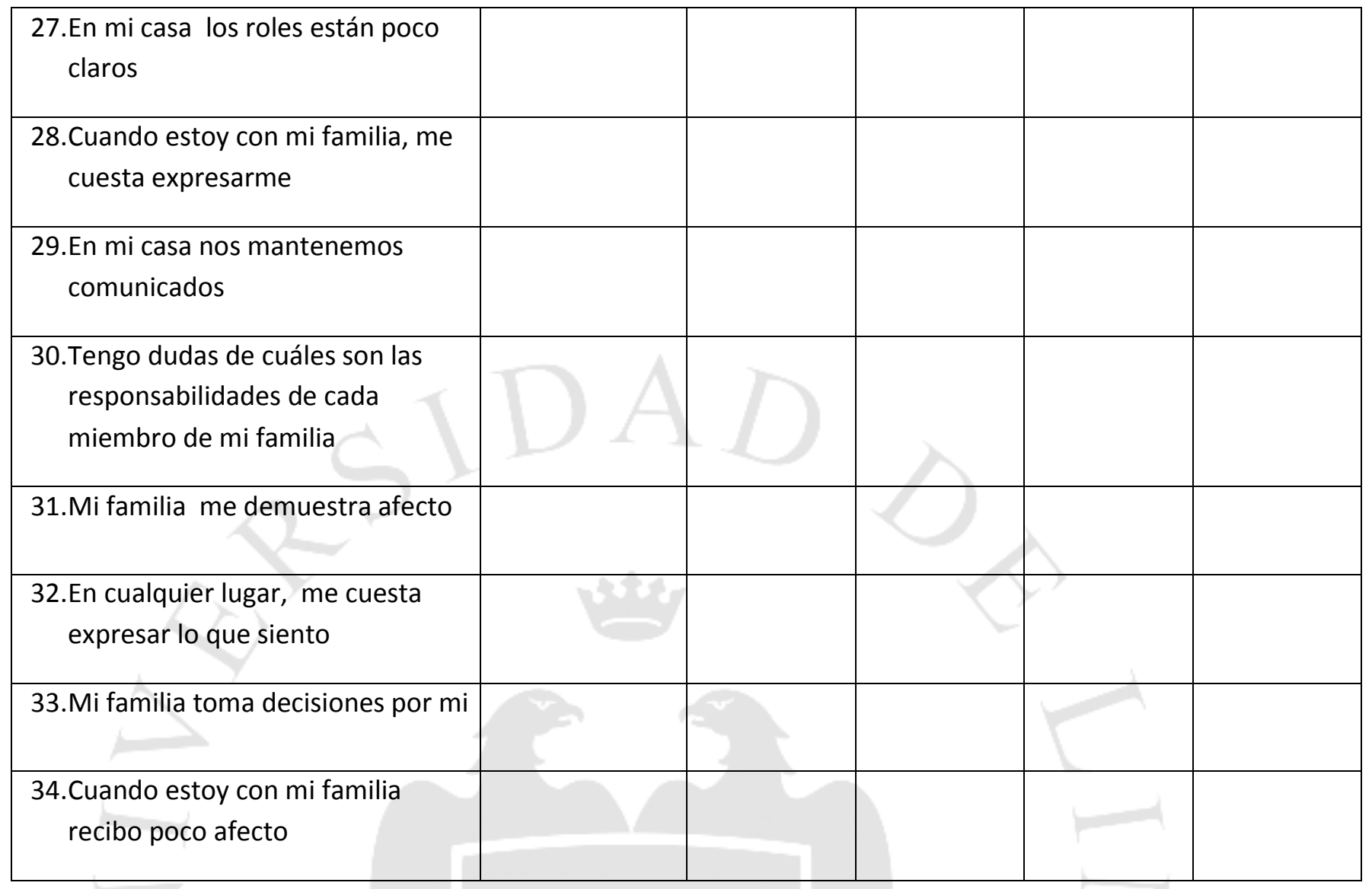




\section{ANEXO 3: CONSENTIMIENTO INFORMADO}

\section{CONSENTIMIENTO INFORMADO}

Acepto participar voluntariamente en esta investigación, conducida por María Jesús Escobar. He sido informado (a) de que la meta de este estudio es realizar la tesis.

Me han indicado también que tendré que responder un test, lo cual tomará aproximadamente 15 minutos.

Reconozco que la información que yo provea en el curso de esta investigación es estrictamente confidencial y no será usada para ningún otro propósito fuera de los de este estudio sin mi consentimiento. He sido informado de que puedo hacer preguntas sobre el proyecto en cualquier momento y que puedo retirarme del mismo cuando así lo decida, sin que esto acarree perjuicio alguno para mi persona. De tener preguntas sobre mi participación en este estudio, puedo contactar a María Jesús Escobar.

Entiendo que una copia de esta ficha de consentimiento me será entregada, y que puedo pedir información sobre los resultados de este estudio cuando este haya concluido. 